NBER WORKING PAPER SERIES

\title{
TO WORK FOR YOURSELF, FOR OTHERS, OR NOT AT ALL? HOW DISABILITY BENEFITS AFFECT THE EMPLOYMENT DECISIONS OF OLDER VETERANS
}

\author{
Courtney Coile \\ Mark Duggan \\ Audrey Guo \\ Working Paper 23006 \\ http://www.nber.org/papers/w23006 \\ NATIONAL BUREAU OF ECONOMIC RESEARCH \\ 1050 Massachusetts Avenue \\ Cambridge, MA 02138 \\ December 2016
}

This research was supported by a grant from the Sloan Foundation (2015-13875) and by the U.S. Social Security Administration through grant \#1 DRC12000002-04 to the National Bureau of Economic Research as part of the SSA Disability Research Consortium. The findings and conclusions expressed are solely those of the author(s) and do not represent the views of SSA, any agency of the Federal Government, or the NBER, nor of the Sloan Foundation. We are grateful to seminar participants at Stanford University, U.C. Berkeley, and the U.S. Treasury Department Office of Economic Policy for helpful comments. The views expressed herein are those of the authors and do not necessarily reflect the views of the National Bureau of Economic Research.

NBER working papers are circulated for discussion and comment purposes. They have not been peer-reviewed or been subject to the review by the NBER Board of Directors that accompanies official NBER publications.

(C) 2016 by Courtney Coile, Mark Duggan, and Audrey Guo. All rights reserved. Short sections of text, not to exceed two paragraphs, may be quoted without explicit permission provided that full credit, including $\odot$ notice, is given to the source. 
To Work for Yourself, for Others, or Not At All? How Disability Benefits Affect the Employment Decisions of Older Veterans

Courtney Coile, Mark Duggan, and Audrey Guo

NBER Working Paper No. 23006

December 2016

JEL No. J22

\begin{abstract} of the Social Security Disability Insurance (SSDI) program.

Courtney Coile

Department of Economics

Wellesley College

106 Central Street

Wellesley, MA 02481

and NBER

ccoile@wellesley.edu

Mark Duggan

Stanford University

Department of Economics

579 Serra Mall

Stanford, CA 94305-6072

and NBER

mgduggan@stanford.edu

Audrey Guo

Department of Economics

Stanford University

579 Serra Mall

Stanford, CA 94305

amguo@stanford.edu
\end{abstract}

The U.S. Department of Veterans Affairs Disability Compensation (DC) program provides disability benefits to nearly one in five military veterans in the US and its annual expenditures exceed $\$ 60$ billion. We examine how the receipt of DC benefits affects the employment decisions of older veterans. We make use of variation in program eligibility resulting from a 2001 policy change that increased access to the program for Vietnam veterans who served with "boots on the ground" in the Vietnam theater but not for other veterans of that same era. We find that the policy-induced increase in program enrollment decreased labor force participation and induced a substantially larger switch from wage employment to self-employment. This latter finding suggests that an exogenous increase in income spurred many older veterans to start their own businesses. Additionally, we estimate that one in four veterans who entered the DC program due to this policy change left the labor force, estimates in the same range as those from recent studies 
Nearly one-third of American men age 55 and above are veterans of U.S. military service. In 2015, the labor force participation rate of male veterans age 55 to 64 was 10 percentage points lower than that of comparable non-veterans, 62 vs. 72 percent. This represents a significant reversal from earlier years. In 2001, for example, the participation rate of older male veterans was actually 0.4 percentage points higher than that of their nonveteran counterparts (68.2 versus 67.8 percent). ${ }^{1}$

There are several possible reasons for the emergence of this gap, including differences in health or in labor market experiences during the recent recession. Another candidate is the growth in the U.S. Department of Veterans Affairs' Disability Compensation (DC) program. The DC program provides benefits to veterans with service-connected disabilities, in order to compensate them for expected earnings losses due to disability. The DC program has grown rapidly in recent years, with the share of veterans receiving benefits rising from 9 percent in 2001 to 19 percent by 2015 and program expenditures reaching $\$ 60$ Billion by the end of this period ${ }^{2}$ As Coile, Duggan, and Guo (2015; hereafter CDG) discuss, this growth in the DC program is due in part to a 2001 liberalization of medical eligibility requirements, when diabetes was made a service-connected condition for Vietnam-era veterans with "boots on the ground" (BOG), a military term for Armed Forces who served in the Vietnam theater, due to concerns about a possible link between the herbicide Agent Orange exposure (used extensively by the U.S. military during the Vietnam War) and diabetes.

\footnotetext{
${ }^{1}$ Calculations from the Bureau of Labor Statistics' Employment Situation of Veterans, 2015 and August 2003 editions (http://www.bls.gov/news.release/vet.nr0.htm -- Table 2b; http://www.bls.gov/news.release/history/vet 06282002.txt-- Table 2).

${ }^{2}$ Calculation from Veterans Benefits Administration's Annual Benefits Report, 2015 and 2001 editions, and from VetPop Model 2014.
} 
The availability of DC benefits, which are not subject to either income or payroll taxation, may affect veterans' employment decisions. While DC benefits for the vast majority of recipients do not decline with earnings, the receipt of benefits - which varied from $\$ 133$ to $\$ 2,907$ per month in 2016 depending on severity of disability - would be expected to decrease labor supply through an income effect. This possibility highlights a classic tradeoff in disability insurance program design. Benefits provide valuable protection against the loss of earnings that may result from disability. However, due to the difficulty of accurately determining disability status, access to benefits may also discourage labor supply among some that are capable of working. An empirical literature going back at least to Parsons (1980) has sought to estimate the share of Social Security Disability Insurance (SSDI) recipients that would have worked in the absence of benefits. More recently, Maestas, Mullen, and Strand (2013) estimate that nearly 30 percent of marginal SSDI recipients could have worked.

The receipt of disability benefits may also affect veterans' decisions regarding whether to be self-employed or work for others. Government programs that provide a guaranteed steady stream of income, even at a relatively low level, may encourage workers to choose self-employment by reducing the risk associated with leaving wage employment. Olds (2016a, 2016b) finds that eligibility for two government programs that provide in-kind benefits, the Supplemental Nutrition Assistance Program (SNAP) and State Children's Health Insurance Program (SCHIP), is associated with an increase in the probability of selfemployment. In related work, Gottlieb, Townsend, and Xu (2016) find that a Canadian reform that expanded job-protected leave for women who recently had a child led to a significant increase in entrepreneurship. 
While these studies suggest that the DC program might affect the employment decisions of veterans, the literature on the DC program itself is very limited, particularly in light of the program's size and recent growth. CDG (2015) show that patterns in the labor force participation of veterans and non-veterans over time are consistent with a role for the DC program, as the timing of the decline in veterans' labor force participation lines up with DC program growth, especially when looking by age group.

However, it is difficult to rule out the possibility that participation could be trending differently for veterans and non-veterans for reasons unrelated to the growth of the DC program. Autor, Duggan, Greenberg, and Lyle (2016; hereafter ADGL) compare changes in labor supply after 2001 for BOG and non-BOG (or NOG) veterans of the Vietnam era; since the Agent Orange decision only affected BOG veterans, NOG veterans can function as a control group. Using this approach, they estimate that DC benefit receipt reduces the probability of being in the labor force by 18 percentage points. An important limitation of the ADGL study is that - given the construction of their analysis sample - they are only able to follow veterans through 2007, when the oldest veterans in their sample are age 61 . As a result, their study period ends before much of the post-2001 growth in the program is realized and before the most common retirement ages of 62 and beyond. Their outcome measures are also limited to individual earnings, so they are unable to examine transitions to self-employment or any effects on spousal labor supply.

Like ADGL, our study makes use of quasi-experimental variation in program eligibility arising from the 2001 Agent Orange decision, which expanded DC eligibility for Vietnam veterans serving in theater (BOG) but not for other veterans of this era, to estimate the effect of the DC program on employment. We have a number of contributions relative to the 
previous literature. We use the Veterans Supplement to the Current Population Survey (CPS), allowing us to analyze data through 2015 and to follow affected veterans through their sixties and beyond. This is potentially important because the effects of the Agent Orange decision may be strengthening over time as DC enrollment continued to grow after 2007 and because veterans close to retirement age may be more responsive to benefit receipt. Additionally, we look at a wider range of employment outcomes than ADGL, including working in self-employment versus working for others, as well as whether DC receipt affects spousal labor supply and family income. Our sample also includes veterans of all service branches rather than just the Army as in ADGL.

We have several key findings. First, DC receipt rises by 10.3 percentage points more for BOG Vietnam-era veterans than for their NOG counterparts in the decade or so between the Agent Orange decision and the last part of our sample period (2010-2015). This confirms that the decision dramatically increased access to DC benefits for BOG veterans. Second, labor force participation falls by 2.5 percentage points more for BOG veterans than for NOG veterans over this period, consistent with the hypothesis that DC benefit receipt reduces employment. Importantly, we find that there is an even larger shift in type of employment, with the probability of self-employment actually rising by 4.1 points and the probability of working for others falling by 6.5 points for BOG relative to NOG veterans over this period. There are also larger decreases in hours and earnings for BOG veterans. There are no significant effects of DC program growth on spousal labor supply, but there is a decline in total family earnings and income. Our findings are generally robust to the inclusion of controls for differential trends in outcomes for BOG and NOG veterans prior to the Agent Orange decision. 
Overall, our estimates suggest that 24 percent of marginal DC beneficiaries (veterans gaining DC benefits as a result of the policy change) would have been in the labor force during the 2010-15 period in the absence of DC benefits. Multiplying our estimate for the effect of DC enrollment on the marginal recipient by the increase in DC enrollment among Vietnamera veterans born between 1944 and 1953, we estimate that nearly one-third of the differential decline in labor force participation among veterans from these cohorts since 2001 is attributable to the growth of the DC program.

In the remainder of the paper, we first provide some background on the DC program and on previous studies relevant to our work. We then discuss our empirical strategy, data, and results. We conclude with a discussion of the possible policy implications of our work and directions for future research.

\section{Background on the DC Program}

The DC program pays benefits to veterans with medical conditions that were caused by or aggravated during their military service. DC recipients also have prioritized access to medical care from the Veterans Health Administration (VHA). DC benefits are not subject to income or payroll taxes and are indexed to the Consumer Price Index. The receipt of labor earnings does not reduce DC benefits for most recipients; in fact, DC benefits can be received simultaneously with earnings, SSDI benefits, Social Security old age benefits, and (in some cases) a military pension. ${ }^{3}$

\footnotetext{
3 Benefits are reduced against labor earnings for beneficiaries with the "Individual Unemployability" designation, as discussed below. The rules for concurrent receipt of military retirement pay and DC benefits are complex. Prior to 2003, retirement pay was essentially reduced dollar-for-dollar against DC benefits. Since 2003, some dual eligibles (those whose disabilities arose from combat or who retired with 20 or more years of service and a CDR of 50 percent or above) have been able to collect both benefits concurrently without offset.
} 
To apply for DC benefits, a veteran first submits an application to a regional office of the Veterans Benefit Administration (VBA). The veteran can claim multiple conditions on the application. The regional office collects information about the veteran's military service and previous health care utilization from the VHA and private providers. This information is used by a Rating Board to decide whether each condition is service-connected, and if so, to set a disability rating for it between 0 and 100 percent using established guidelines. ${ }^{4}$ Often some conditions are approved and others rejected, and the veteran can appeal a rejection or an unexpectedly low rating. The average DC recipient from the Vietnam era had 3.7 serviceconnected disabilities in 2015. The most common approved conditions for veterans of this era are tinnitus, hearing loss, post-traumatic stress disorder, and diabetes, each affecting around 30 percent of DC recipients (Veterans Benefits Administration, 2015).

The ratings for approved conditions are used to determine the veteran's combined disability rating (CDR), using a formula that is similar to adding the individual ratings but has a maximum of 100 percent. $^{5}$ The monthly benefit depends only on the CDR and family status, not on past earnings. This reflects Congressional intent to provide compensation for

Of the nation's 2 million military retirees, about 400,000 currently benefit from these exemptions, while roughly 600,000 face an offset (https://www.cbo.gov/budget-options/2013/44744).

${ }^{4}$ Ratings are in 10 percent increments $(0,10,20$, etc.), though for any given condition, the Board is typically deciding between a few possible ratings, such as 0,30 , or 60 percent. If a veteran is awarded a 0 percent rating for a service-connected disability, he does not receive cash benefits but does qualify for prioritized medical care through the VHA. However, receiving a 0 percent rating for multiple conditions can result in a 10 percent disability payment (Economic Systems Inc., 2004).

${ }^{5}$ If only one condition is approved, the CDR is simply the rating for that condition. If two conditions are approved, then the rating is equal to $R_{1}+\left(R_{2} *\left(1-R_{1}\right)\right)$, with $R_{1}$ and $R_{2}$ equal to the rating for conditions 1 and 2 , and the CDR is rounded to the closest 10 percent increment. For example, if a veteran had one condition rated at 40 percent and a second at 20 percent, then the CDR would be rounded down from 52 to 50 percent. If the second condition had a 30 percent rating, the CDR would be rounded up from 58 to 60 percent. When there are three or more ratings, then the CDR formula is defined similarly, with the rating for the third condition multiplied by $1-\left(\mathrm{R}_{1}+\left(\mathrm{R}_{2} *\left(1-\mathrm{R}_{1}\right)\right)\right.$. 
the average, not individual, loss in earnings capacity due to disability (Economic Systems Inc., 2004). The monthly benefit amount is an increasing function of the CDR, with benefits rising more or less linearly from the 10 percent (\$133 per month in 2016) to 90 percent ( $\$ 1,743$ per month) rating, before jumping to $\$ 2,906$ per month for those with a 100 percent rating. ${ }^{6}$ If his disabilities preclude substantial gainful employment, a veteran with a CDR between 60 and 90 percent may receive the 100 percent CDR benefit even though his CDR is lower, through the Individual Unemployability (IU) designation. ${ }^{7}$ The fraction of DC recipients with an IU designation rose from 5 percent in 2000 to 9 percent by 2013 (CBO, 2014). IU designees do face a loss of benefits if they have labor earnings, as being unable to work is a condition of their higher benefit receipt.

DC recipients can raise their monthly benefit over time if they successfully apply for new health conditions or for a higher rating for existing conditions. ADGL (2016) find that average real monthly benefits for Vietnam-era Army veterans who first received benefits in 2000 increased by 77 percent over the next six years, from $\$ 976$ to $\$ 1,725$,. The CDR for DC recipients rarely declines and the payments typically continue until death. ${ }^{8}$

\footnotetext{
${ }^{6}$ Benefits for recipients with families are modestly higher. For example, a veteran with a 60 percent CDR would receive a monthly benefit of $\$ 1,059$ if single, $\$ 1,156$ if married, and \$1,227 if married with children.

${ }^{7}$ To be eligible for the IU designation, the beneficiary must either have one condition rated at 60 percent or more or have a CDR of 70 percent or more along with at least one condition that has at least a 40 percent rating. See http://www.benefits.va.gov/COMPENSATION/claims-special-individual unemployability.asp for additional information about the IU designation.

8 While the VA can require medical reexamination for DC recipients if it "determines there is a need to verify either the continued existence of the current severity of a disability," in practice the regulations governing reexaminations would seem to ensure that benefits are fairly secure for most recipients. Of particular relevance here, reexaminations are prohibited for veterans over 55 years of age, except in unusual circumstances. www.benefits.va.gov/warms/docs/regs/38cfr/bookb/part3/s3 327.doc
} 
While the medical eligibility criteria for the DC program are generally the same for all veterans and do not change much over time, a major departure from this occurred in July 2001, when the VA liberalized the program's medical eligibility criteria to make diabetes a presumptively service-connected condition for veterans who had served during the Vietnam War era (August 1964 to April 1975) in Vietnam, Cambodia, or Laos. This group encompassed nearly 40 percent of all active duty armed forces who served during the Vietnam War era (3.4 million out of 8.7 million). ${ }^{9}$ The VA's action was prompted by a highprofile report that concluded there is "limited/suggestive" evidence of an association between the use of herbicides such as Agent Orange and Type 2 diabetes (Institute of Medicine, 2000). A presumptive service connection "relieves the veteran of the burden of producing evidence that directly establishes service connection for a specific condition," as he need only show that he has the condition and served in the relevant time and place (Panangala and Shedd, 2014). While the Agent Orange decision was likely the most consequential change to medical eligibility for Vietnam-era veterans, there have been other more recent changes, such as the 2010 addition of ischemic heart disease, Parkinson's disease, and B-cell leukemia to the set of service-connected conditions for BOG veterans, as well as the elimination of the need to document specific events leading to post-traumatic stress disorder for all veterans, also in 2010.10

The DC program has expanded rapidly since the Agent Orange decision. As Figure 1 illustrates, the share of Vietnam veterans receiving DC benefits rose by 2 percentage points

\footnotetext{
${ }^{9}$ http://www.va.gov/opa/publications/factsheets/fs americas wars.pdf

10 There are other conditions that are presumptively service-connected for Vietnam-era veterans, including some granted this status before 2001, though they are much less common than diabetes. For a complete list, see Appendix B of Panangala and Shedd (2014).
} 
in the 15 years before the decision, from 7 to 9 percent, but has more than doubled in the 15 years since, to 19 percent in 2015. Not only has the number of beneficiaries (from all service eras) grown rapidly over time, from 2.2 million in 1986 to 4.2 million in 2015, but the growth has been concentrated in the higher CDRs, as seen in Figure 2. While the number of beneficiaries with a 10 or 20 percent rating has been flat over the past 30 years at 1.2 million, the number with a rating of 70 or above has grown five-fold, to almost 1.5 million, while the number with a 50 to 60 percent rating has nearly tripled, to over 600,000 .

This shift to higher CDRs has an extra effect on program expenditures (Figure 3), as the monthly benefit amount is an increasing function of the CDR. Finally, Figure 4 shows that real DC benefits grew more rapidly than real SSDI benefits between 1999 and 2015, by 63 percent versus 10 percent, and that the average monthly DC benefit is now higher than the corresponding average SSDI benefit. The rapid rise in real DC benefits may reflect both that new DC recipients have higher CDRs and that existing recipients are raising their CDRs over time through appeals and applications for new conditions. In short, the tremendous growth in the DC program among America's veterans since 2001 underscores the need to understand the program's effect on employment decisions.

\section{Previous Literature}

Three strands of the past literature are relevant for our work. The first is the literature on the employment effects of the Social Security Disability Insurance (SSDI) program, as this is the largest disability program in the US and one that has long been studied by researchers. Several recent papers generate plausibly causal estimates of the effect of SSDI receipt on employment by exploiting variation in the assignment of cases to disability 
examiners and judges for review, as individuals vary in how strict they are in granting benefits to applicants with similar health profiles. ${ }^{11}$ Maestas, Mullen, and Strand (2013) use the initial assignment to a disability examiner, while French and Song (2014) use the assignment to administrative law judges during the appeals process; Autor et al. (2015) apply a similar strategy in the Norwegian context. Both US studies find that SSDI benefit receipt reduces employment or labor force participation for the marginal applicant by a similar amount, 26 to 28 percent. ${ }^{12}$ Unfortunately, it is difficult to know how useful these studies might be for predicting the effect of DC receipt on veterans' employment. While there are similarities between the two programs, there are key differences as well, for example the existence of partial disability benefits in the DC program or the fact that DC benefits are not reduced against earnings for most recipients. Moreover, there may be important differences in the characteristics of applicants to the two programs.

More relevant to our study is the past literature on the DC program. However, as noted earlier, this literature is quite limited. CDG (2015) use data from the March Current Population Survey (CPS) for the period 1980 to 2014. They estimate models of labor force participation that include a veteran indicator variable along with age and year indicators. Their key question of interest is how the estimated coefficient on the veteran indicator

\footnotetext{
${ }^{11}$ Papers that precede these recent studies but also contribute to our understanding of the employment effects of SSDI include: Black et al, 2002; Autor and Duggan, 2003; Duggan et al, 2007; Chen and van der Klaauw, 2008; von Wachter et al, 2011.

12 Maestas et al (2013) find that for the 23 percent of applicants estimated to be on the margin of program entry, employment would have been 28 percentage points higher had they not received benefits. However, they note that this finding may overstate the overall employment effect, since estimates of earnings capacity indicate that the average work capacity of this group is far below their pre-disability earnings levels, on the order of one-quarter to one-half of pre-application earnings. They estimate that the likelihood of engaging in substantial gainful activity as defined by the SSDI program (having earnings in excess of $\$ 1,170$ per month, using the 2017 threshold) would be 18 to 19 percentage points higher and the marginal program entrant would earn $\$ 3,800$ to $\$ 4,600$ more per year on average in the absence of SSDI benefit receipt.
} 
changes over time, particularly for different age groups. They find that the participation of male veterans age 25 to 74 has fallen by about 5 percentage points since the late 1990 s relative to that of their non-veteran counterparts. The timing of the decline lines up well with the 2001 Agent Orange decision and other changes that facilitated access to the program. This is particularly true when looking by age group - participation began to fall shortly after 2001 in the older age groups that were populated by Vietnam-era veterans, but fell only starting in 2010 for younger age groups, when similar changes affecting Gulf War veterans went into effect. CDG also find that veterans have become more sensitive to economic shocks in recent years, as the DC program has grown. While this study is highly suggestive of a role for the DC program in veterans' employment decisions, it cannot rule out the possibility that other factors may have also contributed to the emerging gap in labor force participation between veterans and non-veterans.

Autor et al. (2016, or ADGL) is the most relevant for our study, in that it also makes use of variation in DC eligibility arising from the 2001 Agent Orange decision to estimate the employment effects of the program. ADGL use administrative data to construct a large sample of Army veterans born between 1946 and 1951. They find a sharp acceleration in DC enrollment among BOG relative to NOG veterans following the 2001 policy change, primarily due to an influx of new diabetes awards; by 2006, enrollment had risen by an additional 7 percentage points for BOG veterans. They also document that participation fell by an additional 2 percentage points between 2001 and 2007 for BOG vs. NOG veterans. They estimate that 18 percent of individuals who became eligible for the DC program due to the Agent Orange decision dropped out of the labor force, an effect about two-thirds as large as estimates from the SSDI literature. 
As noted earlier, the current study offers a number of innovations relative to ADGL. First, we are able to use more recent data and data on older veterans, which may be important if the Agent Orange decision's impact has continued to grow over time or if the labor supply of older workers is more responsive to benefit receipt. Additionally, our data includes veterans from all service branches, and thus may better reflect the response of the veteran population as a whole. Third, we can look at other employment outcomes beyond own earnings, including spousal and household earnings and income. In lauding the importance of examining family outcomes, Autor et al. (2015) note that there are relatively few studies that consider labor supply responses to income changes in a household context, in part because of the difficulty in identifying a shock to the income of one spouse that does not directly affect the other spouse. The plausibly exogenous variation in DC access arising from the Agent Orange decision may provide such a shock given that the vast majority (more than 98 percent) of Vietnam-era veterans are male.

A fourth novel aspect of our study is that we explore the effect of DC receipt on the decision of whether to be self-employed or work for others. This focus makes the literature on entrepreneurship of interest here and so we review it briefly. As Olds (2016b) notes, social insurance programs can support entry into entrepreneurship by freeing up resources to fund business start-up costs (the "credit channel") and by providing insurance against the consumption shocks that may occur due to the greater volatility of self-employment income (the "risk channel"). While we are not aware of any previous study that has looked at the effect of DC receipt on self-employment, there are a number of papers that shed light on the importance of these two channels. 
Individuals with greater personal wealth may be more likely to start a business, as they are more able to self-finance the initial capital investment. Evans and Leighton (1989) and Evans and Jovanovic (1989) find that the probability of entering self-employment increases with assets. To assess the causality of this association, Holtz-Eakin et al. (1994a, 1994b) and Blanchflower and Oswald (1998) use inheritance receipt as a shock to wealth and find that the probability both of becoming and succeeding as an entrepreneur is increasing in the size of the inheritance. But Hurst and Lusardi (2004) cast doubt on the role of credit constraints by documenting that wealth affects entry into entrepreneurship only at the very top of the income distribution, that wealth is not associated with an increase in the relative likelihood of starting a business in a more capital-intensive industry, and that future inheritances are as predictive of entrepreneurship as past inheritances. They conclude "[borrowing] constraints are not empirically important in deterring the majority of small business formation in the United States."

Individuals with access to a steady source of income apart from their wages may also be more likely to become entrepreneurs, due to the protection it offers against drops in consumption. In two recent studies, Olds (2016a, 2016b) suggests that government policies that provide in-kind benefits - food assistance through the Supplemental Nutrition Assistance Program and health insurance through the State Children's Health Insurance Program - are associated with increases in the probability of entrepreneurship. Both studies make use of changes in eligibility for the programs over time and data from the March CPS. Olds concludes that SNAP and SCHIP eligibility have similar effects on the probability of selfemployment, raising it by 1 to 2 percentage points, or 15 to 20 percent. 
Few studies have explored the effect of government programs that provide cash rather than in-kind benefits on self-employment. Most cash assistance programs, unlike the DC program, are limited to those with low incomes. Those who start successful new businesses lose eligibility for benefits as their incomes increase, so it will be difficult to find an empirical association between benefit receipt and entrepreneurship without access to longitudinal data. Moreover, the programs that have been examined are not similar to the DC program. The UK's Enterprise Allowance Scheme of the 1980s provided cash benefits for up to a year to unemployed people if they started a business (Parker, 2009), so receipt was conditional on entering self-employment. Gottlieb et al. (2016) find that a Canadian reform that extended job-protected maternity leave increased the probability that women would start a business; while this study supports the idea that risk reduction is important, there were no cash benefits involved. Bianchi and Bobba (2013) show that the Progresa conditional cash transfer program in Mexico increased entrepreneurship, but these findings may not translate to a developed country context.

In sum, the past literature suggests that the provision of cash benefits could increase entrepreneurship by reducing consumption risk, but to our knowledge there are no empirical studies that explore this for the DC program or other similar transfer programs. Our paper therefore adds to the literature on entrepreneurship by providing an opportunity to explore this hypothesis.

\section{Data and Empirical Strategy}

The data for the analysis comes from the Veteran's Supplement to the Current Population Survey (VETCPS), which is produced by the U.S. Bureau of Labor Statistics. 
Importantly for our strategy, this survey asks respondents detailed questions about their military service, allowing for the identification of veterans who specifically served in theater ("Boots on the Ground," or BOG) during the Vietnam War. The supplement has been administered in July, August, or September every other year from 1995 to 2009 and yearly since 2009. This allows us to construct a sample that covers the period 1995 to 2015, which includes several years before and nearly fifteen years after the Agent Orange decision.

\section{A. Construction of Analysis Sample}

One challenge in using the VETCPS arises in identifying service era consistently throughout the sample period. Prior to 2005, respondents were only able to report one service era. As a result, those who served in multiple eras, such as in both the Korean and Vietnam wars, might not be identified as Vietnam-era veterans in the data.

To surmount this difficulty, we define Vietnam-era veteran for the purpose of this paper as including all veterans with a year of birth (defined as survey year minus age at survey) between 1944 and 1953, regardless of whether they report that they served in Vietnam. To arrive at this choice, we first combine VETCPS data for those survey years where respondents could indicate multiple service eras, 2005 to 2015 . In Table 1, we report the share of veterans in each birth cohort in these survey years that report serving during the Vietnam War era. To maximize the probability that those in our sample served during the Vietnam era while obtaining the largest sample possible, we implement a decision rule where those cohorts in which at least 75 percent of veterans served during Vietnam are included in the sample. The resulting sample includes the 1944 to 1953 birth cohorts; while we use a 75 percent cutoff, the share serving in Vietnam is over 90 percent for most of these cohorts. Since our sample definition could potentially classify non-Vietnam-era veterans as 
NOG veterans, we test the robustness of our findings to limiting our sample to only reported Vietnam-era veterans, and we obtain qualitatively similar results.

The structure of the CPS as a short panel allows us to create a large sample of personmonth observations. In the CPS, each respondent is surveyed for 4 consecutive months, out of the survey for 8 months, and then surveyed again for 4 months. We include the matched veterans' responses from neighboring monthly CPS surveys, April to December. We are able to do this for every year except 1995 , resulting in a total of 125,711 observations for the period 1995 to 2015. Of this sample 30,873 are unique individuals, and Appendix Figure 1 shows the age distribution of our sample. ${ }^{13}$

The CPS is a useful data source for our project because it includes data on DC receipt as well as on a wide range of employment outcomes. ${ }^{14}$ We look at labor force participation as well as its components, employment and unemployment. We also decompose employment into self-employment and working for others. We make use of data on usual hours worked and earnings, as well as spousal earnings and family earnings and income. Unfortunately, earnings data is only available for the $4^{\text {th }}$ and $8^{\text {th }}$ survey months (outgoing rotation groups), so each veteran only has one earnings observation per year, resulting in a smaller sample size for these regressions. Earnings are adjusted to 2014 dollars, and individuals who are unemployed or out of the labor force receive a value of zero, while those

\footnotetext{
${ }^{13}$ In the 2010-2015 surveys, the Veterans supplement was not collected for all respondents. Therefore, we adjust our sample by dropping missing observations and up-weighting non-missing observations by an adjustment factor determined by each respondent's age group and period of military service, the same methodology the Census Bureau used to create survey weights in 2015.

14 The data on labor market outcomes, DC receipt, and other measures is reported by the respondent or a family member of the respondent. Previous work has found that individuals under-report enrollment in government programs. Our examination of the CPS data suggests that the fraction of veterans reporting DC enrollment is comparable to the fraction one would estimate using aggregate administrative data.
} 
individuals who are working but fail to report earnings are dropped from the earnings regressions (most notably, self-employment earnings are not recorded in the VETCPS so selfemployed individuals are dropped from earnings regressions). Our analysis of spousal and family outcomes is limited to married veterans with non-missing earnings.

Figure 5 shows the composition of new and total DC recipients by single year-of-age in 2015, with the shaded area including the cohorts in our sample born from 1944 to 1953. As this figure shows, these cohorts make up a large share of total DC recipients. Additionally, there are actually as many or more new DC beneficiaries from these cohorts in 2015 as from any other age group, including much younger veterans of recent conflicts in the Middle East. The fact that veterans in their late 60 s continue to join the program in large numbers more than a decade after the Agent Orange decision (and more than 40 years after the conclusion of the Vietnam War) underscores the need to understand the DC program's effects on employment and well-being for many years beyond the 2001 policy change.

\section{B. Empirical Strategy}

Our empirical strategy exploits variation in DC eligibility arising from the 2001 Agent Orange decision, which made diabetes a presumptively service-connected condition for veterans who served with "boots on the ground" in theater during the Vietnam War era. This policy change expanded access to DC benefits by virtually guaranteeing a successful outcome for BOG veterans of this era with diabetes who were making their first application for DC benefits or applying to add diabetes as a new condition.

Diabetes is a common health issue among the older population, with 12 percent of those ages 45 to 64 and 22 percent of those ages 65 to 74 having diagnosed cases in $2014 .{ }^{15}$

${ }^{15}$ Source: http://www.cdc.gov/diabetes/statistics/prev/national/figbyage.htm 
A diagnosis of type 2 diabetes receives a disability rating of 10 percent from the VA if it is manageable by diet alone, but this rises if disease management involves the use of insulin (20 percent), regulation of activities (40 percent), hospitalizations or regular doctor visits (60), and loss of weight and strength or other complications (100).16 Moreover, as veterans tend to apply with multiple conditions, even a veteran receiving a relatively low rating for their diabetes would have a higher CDR if approved for other conditions such as hearing loss. Thus, this policy change made it easier for some BOG veterans to receive a monthly benefit of hundreds or thousands of dollars, while leaving the landscape unchanged for their NOG counterparts. ADGL (2016) show that the share of Vietnam-era DC recipients with diabetes as a service-connected condition was virtually zero until 2001 for both BOG and NOG veterans; between 2001 and 2006, this share rose rapidly for BOG veterans but remained negligible for NOG veterans.

We make use of this quasi-experimental variation in DC access by estimating models of the following form for our sample of Vietnam-era veterans:

$$
Y_{i t}=\alpha_{t}+\gamma_{0} B O G_{i}+\sum \gamma_{t} * B O G_{i}+X_{i t}{ }^{\prime} \beta+\varepsilon_{i t}
$$

where $\mathrm{Y}$ is an outcome measure such as DC receipt or employment for individual $\mathrm{i}$ in year $\mathrm{t}$, $\alpha_{t}$ includes both year and month fixed effects, and BOG is an indicator set to one if the veteran served with boots on the ground. The next term represents the interaction between BOG and year. Including a separate interaction term for each year for which we have a Veterans Supplement (14 years in all) would generate imprecise estimates given our sample size.

\footnotetext{
16 The schedule for rating disabilities is available at: http://www.benefits.va.gov/warms/bookc.asp\#p
} 
Therefore, we group our data into four (non-equal) periods: 1995-1997, 1999-2001, 20032009, and 2010-2015. We interact an indicator for each of these periods with BOG, except for 1999-2001, which we use as the reference period as it includes the years immediately before the decision took effect. ${ }^{17}$

The coefficient on the main BOG variable captures the difference in outcomes between BOG and NOG veterans in the reference period, while the coefficients on the interaction terms allow us to see how the BOG-NOG difference evolves after the decision, both in the short and medium term (2003-09) and in the long term (2010-15). The interaction of BOG with the 1995-1997 indicator allows us to explore whether there is any significant trend in the BOG-NOG difference prior to the Agent Orange decision. The period during which we can look for a pre-trend is somewhat constrained by the fact that the VETCPS begins in 1995. However, as an additional robustness check, we also include an interaction between BOG and a linear year pre-trend in some specifications, and find that our results are generally robust to the inclusion of this additional control (shown on only our first results table, for conciseness). ${ }^{18}$ Finally, $\mathrm{X}$ is a vector of individual characteristics, including individual age fixed effects and race and education indicators. And because we include matched observations from neighboring months of the CPS survey, we cluster our regressions at the person level.

In Table 2, we provide summary statistics for the BOG and NOG veterans in our sample, using data only for the years prior to the policy change (1995-2001). BOG veterans make up 46 percent of our sample. The BOG sample is $88 \%$ white, $74 \%$ married, and a

\footnotetext{
17 The 2001 Veterans Supplement was collected in August, shortly after the VA's "final rule" on the Agent Orange decision on July 9, 2001. Thus data in the 2001 Supplement is unlikely to be affected by the decision. 18 The linear year trend is defined to be year-2001 until 2001 and 0 thereafter.
} 
majority has either some college $(25 \%)$ or a college degree (35\%) The differences between the average characteristics of the BOG and NOG samples are fairly small but often statistically significant. In the analysis we include controls for race and education as well as a BOG indicator that controls for differences in outcomes between BOG and NOG veterans in the baseline period (1999-2001) that may occur for any reason. Our key identifying assumption is that there is no other reason for outcomes for BOG and NOG veterans to be trending differently over time after 2001 besides the growth of the DC program. We provide some exploration of this issue with respect to health below.

C. Trends in Labor Force Participation Since 1995

Before moving to our results, we provide some additional motivation for our study and choice of cohorts. Figure 6 shows trends over time in the labor force participation rate of veterans and non-veterans in the 1944 through 1953 cohorts. The rates for veterans and non-veterans are virtually identical from 1995 through the early 2000s, declining over time (as expected) as the cohort ages. The drop for veterans is much more rapid thereafter, however, such that the participation rate of veterans is 10 percentage points lower than that of non-veterans by 2015. We can also examine how the participation rate for veterans and non-veterans in a specific age group, 55 to 69, is changing over time, as seen in Figure 7.19 This figure adjusts for age to address the possibility of different age composition in the veteran and non-veteran group. The two rates are very similar and rising until the early 2000s, but thereafter, the participation rate for non-veterans continues to climb while that

\footnotetext{
${ }^{19}$ This age range includes the 1926 to 1940 cohorts in 1995 and gradually changes to include the 1946 to 1960 cohorts by 2015. One advantage of this comparison is that it allows one to explore whether veterans from an earlier era (e.g. Korea War) tended to leave the labor force earlier than non-veterans, which could explain the Figure 6 divergence. But it appears that this gap opens up only as the Vietnam-era veterans in our analysis sample enter the 55 to 69 age range.
} 
for veterans does not. Thus whether focusing on a specific birth cohort or age group, the participation rates of veterans and non-veterans diverge after 2001. In our analyses below, we explore whether growth in DC enrollment is an important contributor to this divergence.

\section{Results}

We now turn to the empirical analysis, beginning with the results for DC receipt in Table 3. We find that there is a baseline difference in DC receipt between BOG and NOG veterans in the reference period (1999-2001), with BOG veterans being 8.0 percentage points more likely to be receiving benefits and 2.8 points more likely to have a CDR of 50 percent or more in our preferred specification (column 2). This difference likely reflects that those who served with boots-on-the-ground have more service-connected disabilities that qualify them for benefits.

Of greater interest to us is how this difference is changing over time. We find that the share of BOG veterans receiving benefits is 2.8 percentage points higher in the short-term (2003-2009) and 10.3 points higher in the long-term (2010-2015) as compared to the baseline difference. As year fixed effects pick up any trends over time in receipt that are common to BOG and NOG veterans, these interaction terms show the differential increase for BOG veterans. We similarly find that the probability of having a CDR of 50 percent or above grows by an additional 3.9 percentage points in the short term and 8.7 points in the long term for BOG veterans. These effects are very large relative to the share of the sample receiving DC benefits, 15.3 percent, or to the share with a CDR of 50 percent or above, 6.1 percent. One likely explanation is that many BOG veterans who were already receiving DC benefits enjoyed an increase after 2001 as a result of the policy change. Thus the number 
receiving a high CDR reflects the effect both for new recipients and for incumbents who benefit from a "promotion" to a higher CDR. The inclusion of controls for pre-trends has little impact on the results and these coefficients are statistically insignificant. Overall, this table confirms that the effect of the Agent Orange decision on DC receipt is large and growing substantially over time.

In Table 4, we shift to employment outcomes. We find that BOG veterans are 2.9 percentage points less likely to be in the labor force in the reference period. This difference grows by 1.1 points in the short term, though the effect is insignificant, and by 2.5 points in the long term, an effect that is significant at the 10 percent level. Again, the coefficient on the interaction of BOG and the earlier period (1995-97) show no indication of a differential trend in participation for BOG vs. NOG veterans prior to the reference period.

As people can report that they are out of the labor force for various reasons, we also explore how the growth of the DC program is associated with a rise in non-participation of different types. We find that essentially all of the growth in non-participation occurs in people reporting themselves as retired, while there is virtually no increase in people reporting themselves as disabled or out of the labor force for other reasons. The result with respect to disability is important because it casts doubt on an alternative explanation for our findings, namely that the participation of BOG and NOG veterans trends differently over time because the health of BOG veterans is deteriorating more rapidly. If this were the case, we might expect BOG veterans to be increasingly likely to say they are out of the labor force due to disability, but we do not find that. In results not shown here, we investigate whether BOG veterans are increasingly likely to report that they have a work-limiting disability and also 
find no evidence of this. ${ }^{20}$ Thus, it seems quite likely that the greater labor force withdrawal of BOG vs. NOG veterans after 2001 can be attributed to the growth of the DC program.

In Table 5, we look more closely at employment outcomes. The first and last sets of columns show that the post-2001 decrease in labor force participation occurred entirely via a decrease in employment, with no change in unemployment, although the interaction between BOG and the 2010-15 period indicator in the employment model is not significantly different from zero. Of even greater interest, the two middle sets of columns indicate that the growth of the DC program after 2001 is associated with a 6.5 percentage point decrease in the probability of BOG veterans working for others in the long term (2010-15) and a 4.1 point increase in the probability of self-employment. The shift into self-employment is quite large relative to the 10.3 percentage point mean rate in the sample, and also relative to the 2.5 point decrease in participation.

To explore these results further, in Table 6 we break self-employment down into incorporated and unincorporated self-employment; incorporating is generally viewed as reflecting a more serious commitment to the new venture (Olds, 2016a). We find that the probability of both incorporated and unincorporated self-employment rise for BOG vs. NOG veterans in the long term, with increases of 1.4 and 2.7 points, respectively. We also look at the rise by industry type, breaking out the two most common industries for the selfemployed in our sample, construction and professional/business services, from all other industries. ${ }^{21}$ We find that for BOG veterans, self-employment in professional/business

\footnotetext{
${ }^{20}$ ADGL also have an interesting test of this alternative explanation, where they split their sample by year of birth (YOB) and show that the break in outcomes between BOG and NOG veterans for both YOB groups occurs after 2001 and not when veterans reach any particular age - the latter would be more likely if declines in participation were health-related.

${ }^{21}$ Appendix Figure 2 shows the industry breakdown for veterans both self-employed and working for others.
} 
services rises by 1.3 points and in all other industries rises by 2.7 points; there is no differential increase over time in self-employment in construction. By showing rises in incorporated and unincorporated self-employment and in different industries, the results on this table confirm that the shift to self-employment is an important part of veterans' response to the growth of the DC program. And although self-employment earnings are not observed in the VETCPS, Appendix Figure 3 compares the distribution of log annual earnings for self-employed and not self-employed Vietnam-era veterans in the March CPS. While there is a greater mass of zero earnings for the self-employed, their mean log earnings are relatively close to the mean for other workers.

Finally, we turn to the effects of DC program growth on hours and earnings, as reported in Table 7, and on spousal and household outcomes, as reported in Table $8 .{ }^{22}$ In the long-term (2010-15), usual hours per week falls by an additional 1.1 hours for BOG veterans. Most of this decrease can be explained by the 2.5 percentage point drop in participation reported on Table 3, which would cause usual hours per week to fall by 1 hour if all veterans worked 40 hours per week. ${ }^{23}$ This suggests that there may have been little labor supply response on the intensive margin, which we confirm in results not shown here. The probability of any weekly earnings falls by a significant 4.2 points for BOG veterans in the long term, a bit more than the estimated participation effect, though this is estimated using a smaller sample; mean weekly earnings fall by an insignificant $\$ 23$, which can be compared to a mean of $\$ 656$, and log earnings fall as well. Overall, the earnings results

\footnotetext{
${ }^{22}$ We were also interested in exploring the heterogeneity in the effects of DC program growth by education level. Unfortunately, due at least in part to the size of our sample, the coefficients from models using education sub-samples or interaction terms were too imprecisely estimated for us to be able to conclude much from this exercise.

${ }^{23}$ Only about ten percent of our sample works part-time.
} 
confirm that there is a reduction in work for BOG veterans after the expansion of the DC program.

The results for spousal earnings are suggestive of a decrease in spousal employment, which is consistent with a positive shock to household income due to the growth of the DC program. However, while the magnitudes of the coefficients are similar to those for the veterans themselves, the coefficients are not statistically significant. The results on Table 8 do show a 2.7 percentage point increase in the long-term in the probability of having family income less than $\$ 50,000$ and a large decrease in log combined wages for BOG veterans, both of which are statistically significant. The former suggests that even though families may be receiving more in DC benefits, this is not sufficient to make up for the loss of earnings, leading some families to fall below the $\$ 50,000$ threshold. To the extent that decreases in participation are voluntary, this reflects families choosing to have lower income and more leisure time or more time for unpaid caregiving as a result of the enhanced access to DC benefits.

\section{Discussion}

In this study, we explore the effect of VA Disability Compensation benefits on employment outcomes, exploiting variation in benefit access arising from the 2001 Agent Orange decision, which affected only Vietnam-era veterans who served with boots-on-theground in the Vietnam theater. We estimate that by the latter part of our sample period (2010-2015), there was a 10.3 percentage point increase in program participation for the BOG veterans as a result of the Agent Orange decision, which increased access to the DC program. We further find that labor force participation fell by 2.5 percentage points for this 
group (relative to the change for NOG veterans) by the end of the sample period. The implied effect of program receipt for the marginal recipient is to decrease labor force participation by an estimated 24 percentage points. ${ }^{24}$ This effect is one-third larger than that previously estimated by ADGL for the DC program, with the difference likely due to our study's ability to follow veterans for more years after the Agent Orange decision and to include older veterans in the sample. The effect here on participation is similar to those estimated by Maestas et al (2013) and French and Song (2014) for the SSDI program, despite significant differences between the DC and SSDI programs both in program provisions and recipients' characteristics. However, the implied effect of program receipt on earnings could be quite different, as Maestas et al estimate that the marginal SSDI recipients in their sample would have annual earnings of $\$ 3,800$ to $\$ 4,600$. The employed BOG veterans in our sample (prior to the 2001 policy change) have median weekly earnings of around $\$ 1000$ (in 2015 dollars).

Our other central finding is that the growth of the DC program was associated with a significant shift away from working for others and into self-employment. Specifically, we find that by the end of our sample period, there was a 4.1 percentage point increase in selfemployment for BOG veterans, whose DC eligibility may have been affected by the Agent Orange decision. By the same logic used above, this implies that 40 percent of those induced to go on the DC program by the easier access to DC benefits switched to self-employment. This is a novel finding - while Olds (2016a, 2016b) finds that several in-kind benefit programs are associated with an increase in entrepreneurship, ours is the first study to our knowledge to find that an unconditional cash transfer program encourages recipients to

\footnotetext{
${ }^{24}$ This follows ADGL (2016) and assumes no labor supply effect for those who would otherwise be on the DC program but experienced an increase in monthly benefits due to an additional diabetes diagnosis.
} 
start their own business. Further research to see if these results generalize to other benefit programs offered to younger or non-veteran workers would be helpful.

Our estimates can be used to conduct a "back-of-the-envelope" calculation of the share of the recent decline in the labor force participation of Vietnam-era Veterans that can be attributed to the growth of the DC program. Between 2000 and 2013 (the mid-points of our pre-policy reference period and final sample period, respectively), DC enrollment climbed by 9.2 percentage points for NOG veterans and for 19.5 percentage points for BOG veterans, according to our estimates. ${ }^{25}$ We estimate that DC receipt decreases labor force participation by 24 percentage points for the marginal BOG recipient, and we assume for the purpose of this calculation that the labor supply response would be the same for NOG recipients. Combining these values along with the share of BOG and NOG veterans in the population, we estimate that the growth in the DC program led to a 3.2 percentage point decline in the labor force participation of Vietnam-era veterans, of which 1.9 points is the decrease in participation for BOG veterans and 1.3 points is the decrease for NOG veterans. ${ }^{26}$ BOG veterans are only 40 percent of the veteran population, but have twice as large an increase in DC receipt, and thus contribute more to the decline in participation. The gap in participation between veterans and non-veterans rose by 10.6 percentage points during this period, as calculated from the data underlying Figure 6. This suggests that the growth of the

\footnotetext{
25 The estimated increase for our sample may differ from that for all Vietnam-era veterans shown in Figure 1 given that some Vietnam-era veterans were born before 1944 and others were born after 1953. We obtain a value of 9.2 by taking the average of the individual year coefficients for 2010-2015 from the DC receipt models in Table 3 (year coefficients not shown on the table); as 1999-2001 is the omitted period, this represents the growth in DC receipt for NOG veterans since this time. In these models, we estimate that DC enrollment grew by an additional 10.3 percentage points for BOG veterans. This results in a total growth in DC enrollment of 19.5 percentage points for BOG veterans between 2000 and 2013.

${ }^{26}$ These calculations are made as follows. For BOG veterans: $19.5 \%$ rise in DC enrollment $x 24 \%$ participation effect $\times 40 \%$ share in population $=1.87$. For NOG veterans: $9.2 \%$ x $24 \%$ x $60 \%=1.32$.
} 
DC program can explain nearly one-third of the gap in labor force participation between older veterans and non-veterans that emerged during this period.

Our study provides new estimates of the potential importance of income effects of unconditional cash transfers on labor force participation. Studies of the DC program offer a unique opportunity to estimate income effects because benefits are not generally reduced against earnings, as they are for many other government programs such as SSDI. Some policy makers and public intellectuals have recently called for replacing some traditional welfare and social insurance programs with an unconditional cash transfer to all families. Our estimates may shed some light on the possible effects of such a policy, though we caution that it is difficult to know how well our findings would generalize beyond the population we study, which is an older veteran population. ${ }^{27}$

We also note that our study provides only one piece of the evidence that would be necessary to provide a complete welfare analysis of the DC program. Veterans who may be induced to withdraw from the labor force by enhanced access to DC benefits consume more leisure, which has a value to them that we do not estimate in our study. The increase in leisure will have even greater value if these veterans are in poor health and have a high disutility of work, as may be likely. The ability to shift to self-employment may reflect another benefit of the DC program, newly discovered in this study. To the extent that failures in credit markets or other market failures impede individuals' ability to start a business and the DC program eases these constraints, the value of this benefit also needs to be estimated and incorporated in any welfare analysis. Another important piece of the puzzle is the

\footnotetext{
${ }^{27}$ An additional caveat is that incentive (rather than just income) effects may be important for the 9 percent of DC recipients with the IU designation or for any DC recipients hoping to qualify for IU benefits in the future.
} 
interaction between the DC program and other government programs, particularly the SSDI program. Muller et al (2014) find that many of the most disabled DC recipients were receiving SSDI benefits prior to their DC award, a scenario that may affect the value of the DC award to those recipients. The interactions between the DC and SSDI programs represent a fruitful area for research, and one that we continue to pursue in ongoing work.

Programs such as DC where benefits may be collected even if recipients have labor earnings have income effects but no substitution effects. ${ }^{28}$ As a result, there are welfare losses from raising the tax revenues needed to pay DC benefits, currently $\$ 60$ Billion per year, but not from the changes in veterans' participation induced by the change in program incentives. Furthermore, the moral hazard framing implicit in a study of the labor supply effects of a social insurance program may be less appropriate if the goal of the DC program is to compensate veterans for injuries suffered in service of the country rather than to make up for specific disability-related earnings losses. Some features of the DC program, such as the fact that benefits do not depend on the individual's own past earnings and generally last until death and that medical reexaminations are essentially prohibited past age 55, may be viewed as more consistent with the former. Clearly, much more work is needed to understand all of the implications of this program, which serves a large and rapidly-growing share of the veteran population with a correspondingly fast-rising price tag.

\footnotetext{
${ }^{28}$ As we mention above, approximately 9 percent of DC recipients have the individual unemployability (IU)
} designation, and therefore benefits would decline for this group if earnings increased substantially. 


\section{References}

Autor, David H., Mark Duggan, Kyle Greenberg, and David S. Lyle (2016). "The Impact of Disability Benefits on Labor Supply: Evidence from the VA's Disability Compensation Program," American Economic Journal: Applied Economics 8(3):31-68.

Autor, David H. and Mark G. Duggan. (2003). "The Rise in the Disability Rolls and the Decline in Unemployment," The Quarterly Journal of Economics 118(1):157-205.

Autor, David, Andreas Kostol, and Magne Mostad (2015). "Disability Benefits, Consumption Insurance, and Household Labor Supply," mimeo.

Bianchi, Milo and Matteo Bobba (2013). "Liquidity, Risk, and Occupational Choices," Review of Economic Studies 80(2):491-511.

Black, Daniel, Kermit Daniel, and Seth Sanders (2002). "The Impact of Economic Conditions on Participation in Disability Programs: Evidence from the Coal Boom and Bust." American Economic Review 92(1) 27-50.

Blanchflower, David G. and Andrew J. Oswald (1998). "What Makes an Entrepreneur?" Journal of Labor Economics 16(1):26-60.

Bound, John (1989). "The Health and Earnings of Rejected Disability Insurance Applicants." American Economic Review 79(3): 482-503.

Chen, Susan and Wilbert van der Klauuw (2008). "The Work Disincentive Effects of the Disability Insurance Program in the 1990s." Journal of Econometrics 142: 757-78.

Coile, Courtney, Mark Duggan, and Audrey Guo (2015). “Veterans' Labor Force Participation: What Role Does the VA's Disability Compensation Program Play?" American Economic Review: Papers \& Proceedings 105(5):131-146.

Duggan, Mark, Perry Singleton, and Jae Song (2007). "Aching to Retire? The Rise in the Full Retirement Age and its Impact on the Disability Rolls." Journal of Public Economics, 1327- 1350.

Economic Systems Inc. (2004). "VA Disability Compensation Program: Legislative History," report prepared for VA Office of Planning, Policy, and Preparedness.

Evans, David S. and Boyan Jovanovic (1989). "An Estimated Model of Entrepreneurial Choice Under Liquidity Constraints," Journal of Political Economy 97(4):808-827.

Evans, David S. and Linda S. Leighton (1989). "Some Empirical Aspects of Entrepreneurship," American Economic Review 79(3):519-535. 
French, Eric and Jae Song (2014). "The Effect of Disability Insurance Receipt on Labor Supply." American Economic Journal: Economic Policy 6(2): 291-337.

Gottlieb, Joshua D., Richard R. Townsend, and Ting Xu (2016). "Experimenting with Entrepreneurship: The Effect of Job-Protected Leave," Tuck School of Business Working Paper No. 2714577.

Holtz-Eakin, Douglas, David Joulfaian, and Harvey S. Rosen (1994a). "Sticking it Out: Entrepreneurial Survival and Liquidity Constraints," Journal of Political Economy 102(1):53-75.

Holtz-Eakin, Douglas, David Joulfaian, and Harvey S. Rosen (1994b). "Entrepreneurial Decisions and Liquidity Constraints," RAND Journal of Economics 25(2):334-347.

Hurst, Erik and Annamaria Lusardi (2004). "Liquidity Constraints, Household Wealth, and Entrepreneurship," Journal of Political Economy 112(2):319-347.

Institute of Medicine (2000). Veterans and Agent Orange: Herbidice/Dioxin Exposure and Type 2 Diabetes - Report of the Committee to Review the Evidence Regarding the Link Between Exposure to Agent Orange and Diabetes. Washington, D.C.: National Academy Press.

Maestas, Nicole, Kathleen J. Mullen, and Alexander Strand (2013). “Does Disability Insurance Receipt Discourage Work? Using Examiner Assignment to Estimate Causal Effects of SSDI Receipt," American Economic Review 103(5):1797-1829.

]Muller, Scott, Nancy Early, and Justin Ronca (2014). "Workers Who Apply for Social Security Disabled Worker Benefits After Receiving a Department of Veterans Affairs Rating of "Total Disability" for Service-Connected Impairments: Characteristics and Outcomes," Social Security Bulletin 74(3):1-37.

Olds, Gareth (2016a). "Food Stamp Entrepreneurs," Harvard Business School Working Paper 16-143.

Olds, Gareth (2016b). "Entrepreneurship and Public Health Insurance," Harvard Business School Working Paper 16-144.

Panangala, Sidath and Daniel Shedd (2014). "Veterans Exposed to Agent Orange: Legislative History, Litigation, and Current Issues," Congressional Research Service Report 7-5700.

Parker, Simon C. (2009). The Economics of Entrepreneurship. Cambridge: Cambridge University Press.

Parsons, Donald O. (1980). “The Decline in Male Labor Force Participation," Journal of Political Economy 88(1):117-134. 
Von Wachter, Till, Jae Song, and Joyce Manchester (2010). "Trends in Employment and Earnings of Allowed and Rejected Applicants to the SSDI Program" American Economic Review 101(7): 3308-3329. 


\section{Figure 1: Growth in Vietnam Era DC Recipients, 1986-2015}

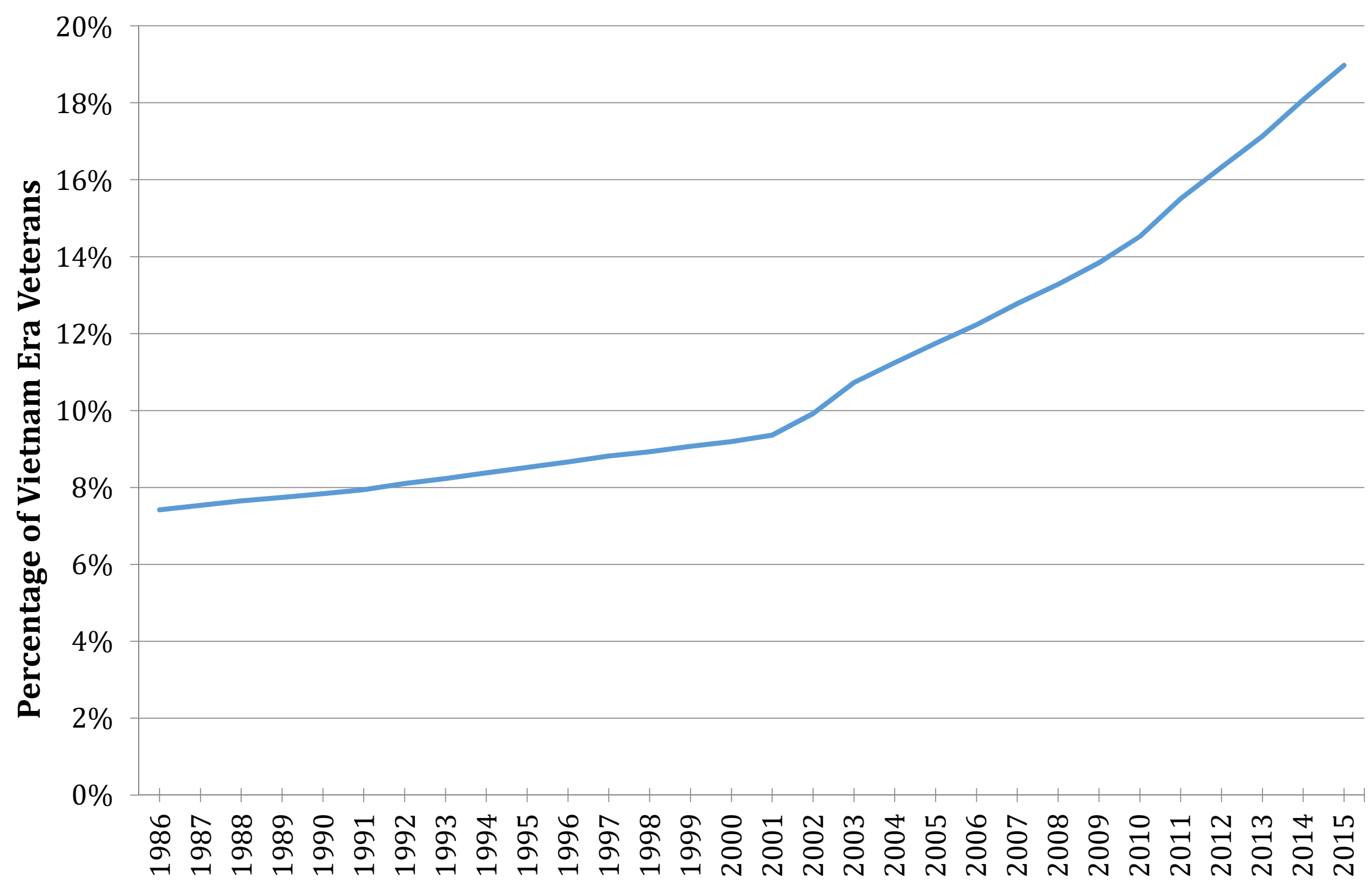


Figure 2: Growth in DC Beneficiaries by CDR, 1986-2015

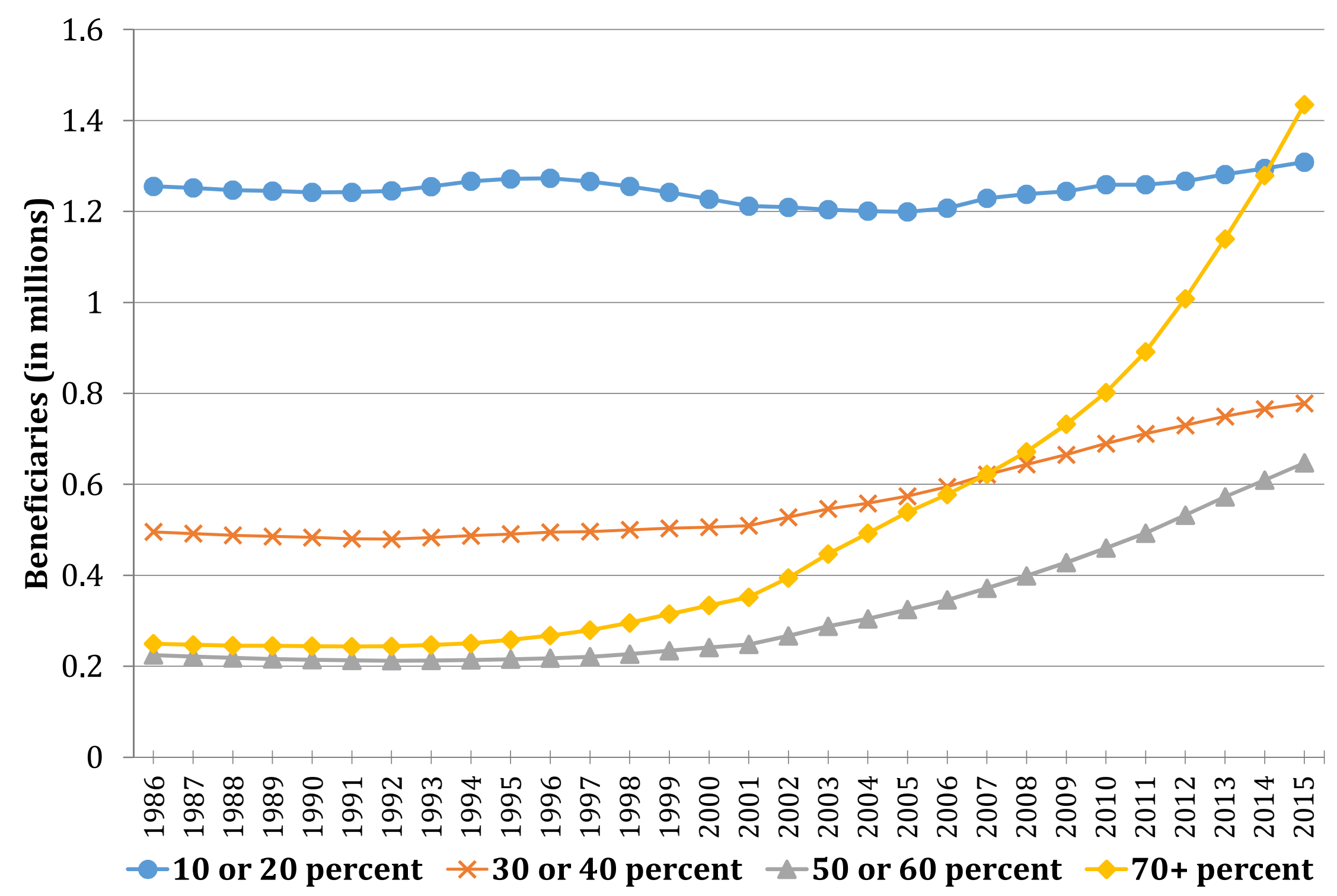


Figure 3: Growth in DC Expenditures by CDR, 1999-2015

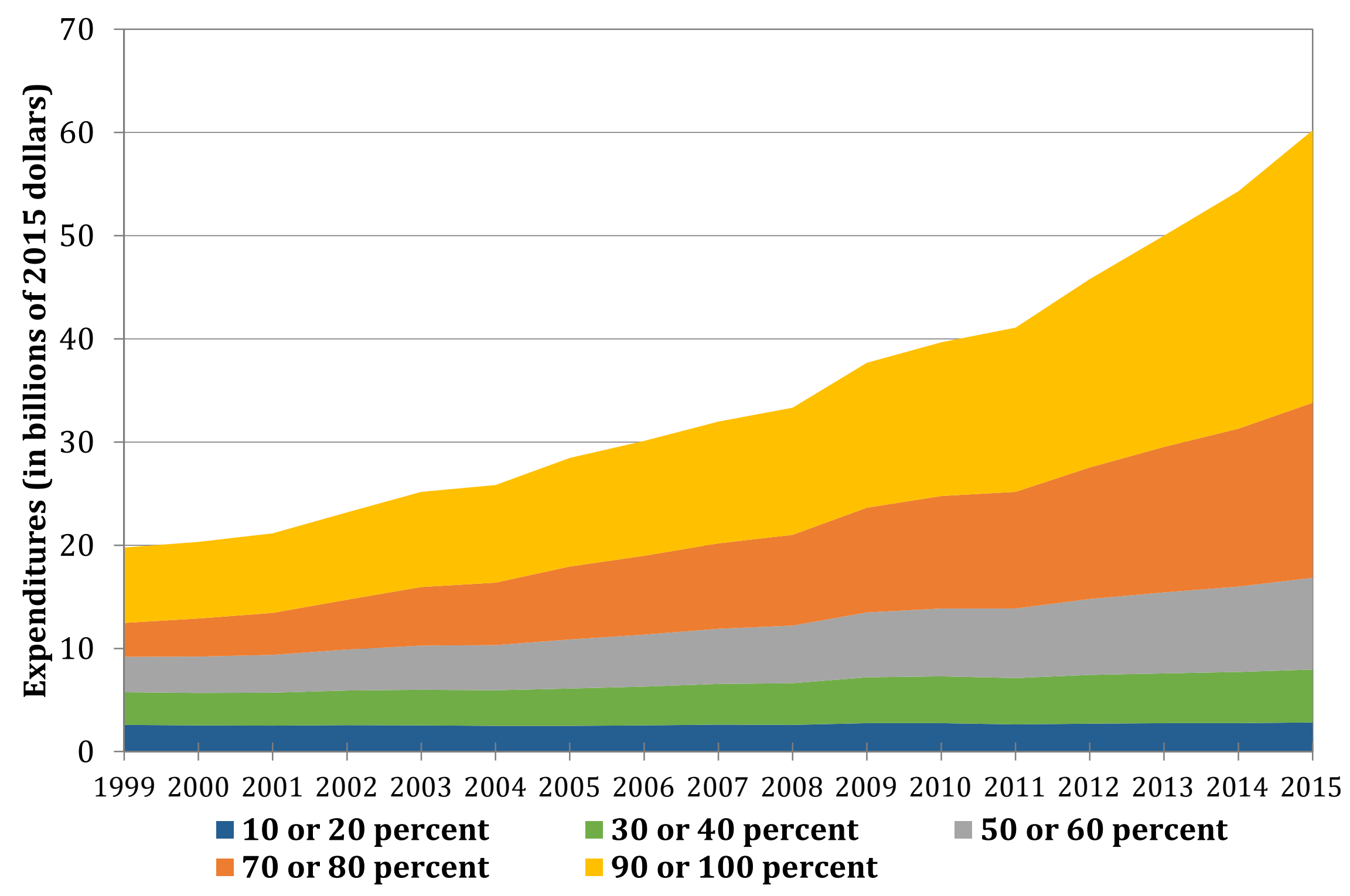


Figure 4: Average Monthly Benefit for Vietnam Era DC Recipients, 1999-2015

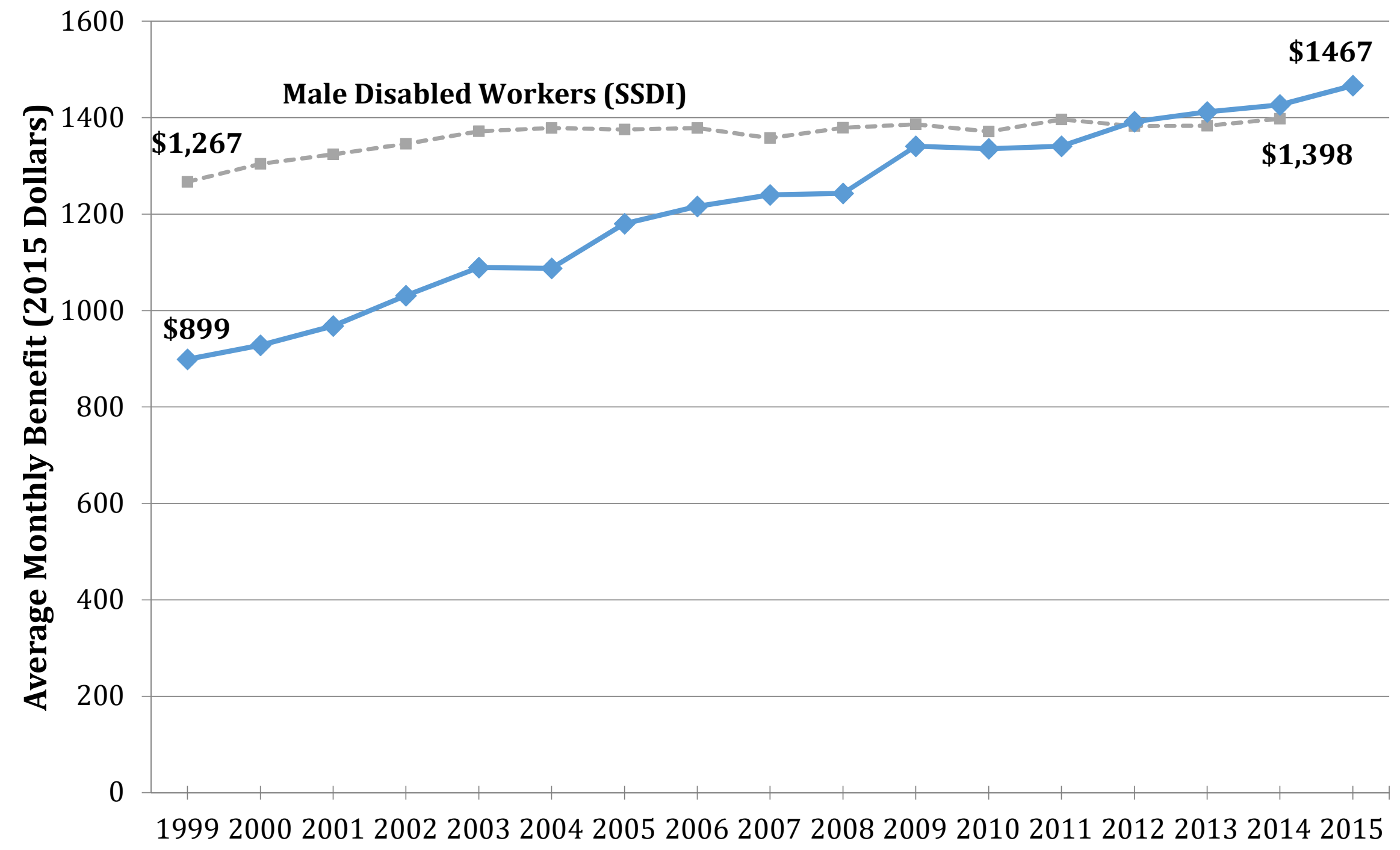

Source: VBA Annual Benefits Reports (1999-2015) and BLS CPI-U; Annual Statistical Report on the Social Security Disability Insurance Program, Table 36 


\section{Figure 5: VADC Compensation Recipients by Age, FY 2015}

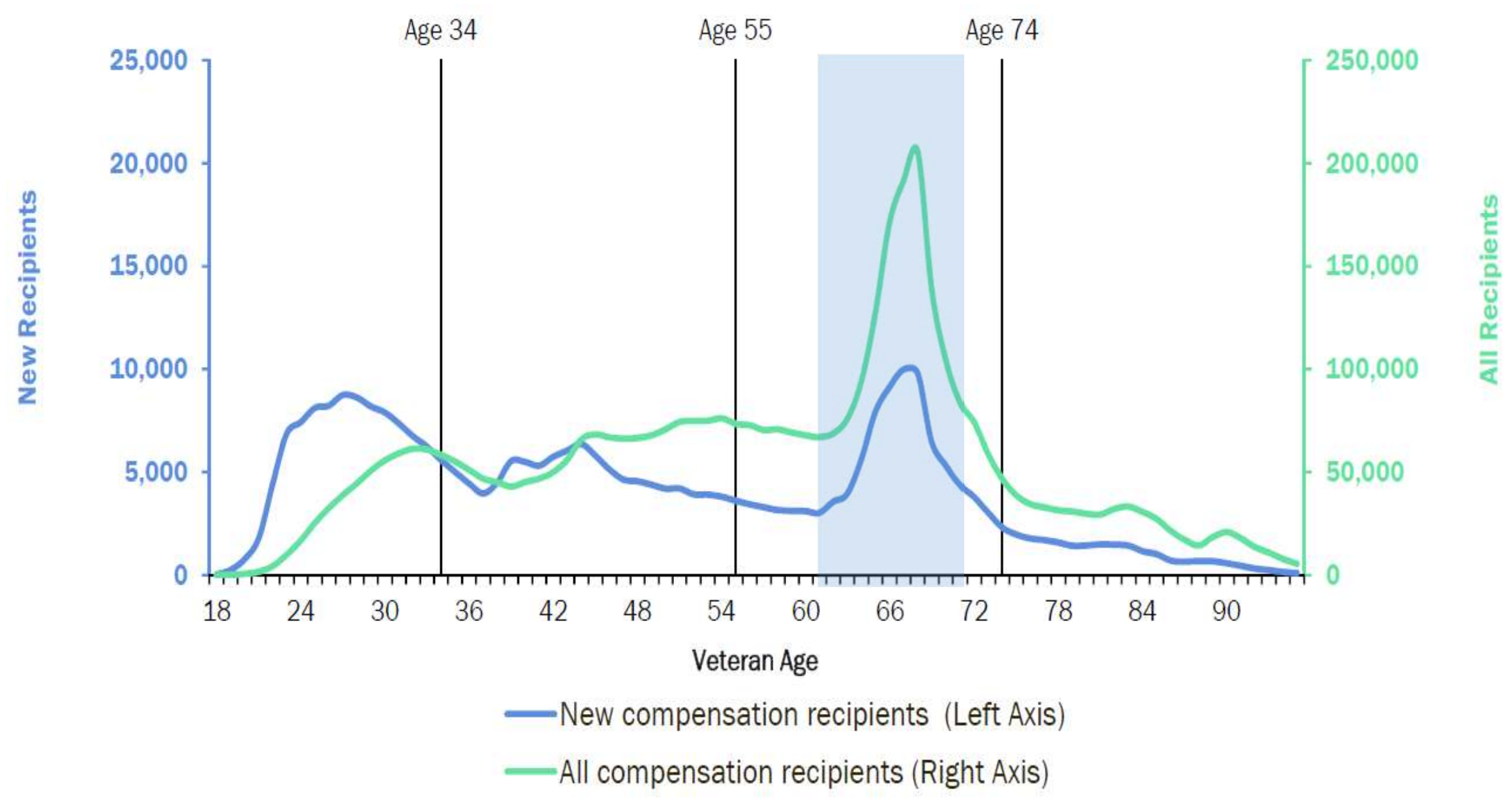

Our Veterans CPS analysis sample is aged 62 to 71 in 2015.

Source: VBA Annual Benefits Report, 2015 
Figure 6: Labor Force Participation for Males Born 1944 - 1953, by Veteran Status, 1995-2015

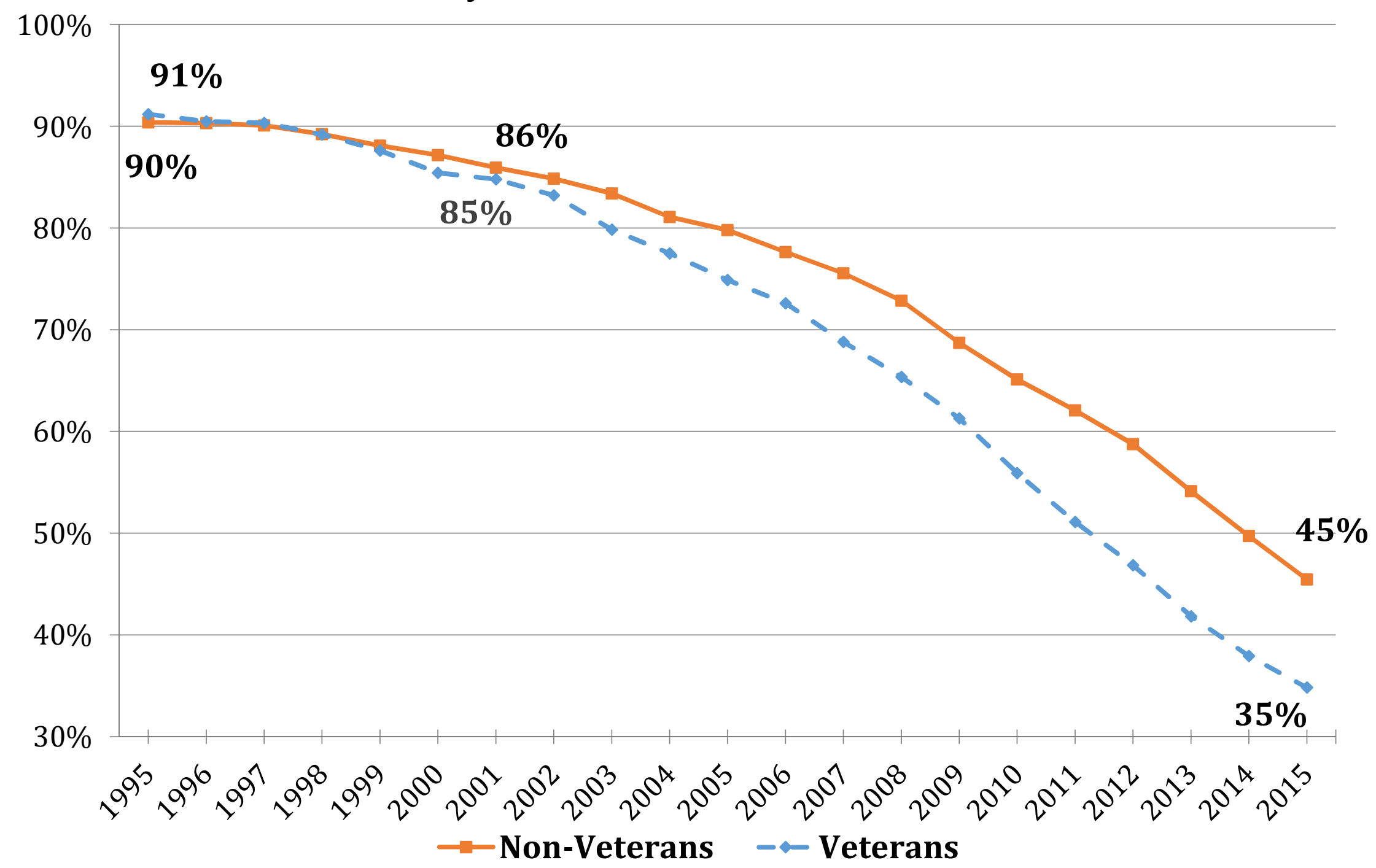

Annual averages for males with YOB 1944-1953 (defined as survey year minus age) in monthly CPS surveys from January 1995 to December 2015. 


\section{Figure 7: Age-Adjusted Labor Force Participation for Males Age}

55-69, by Veteran Status, 1995-2015

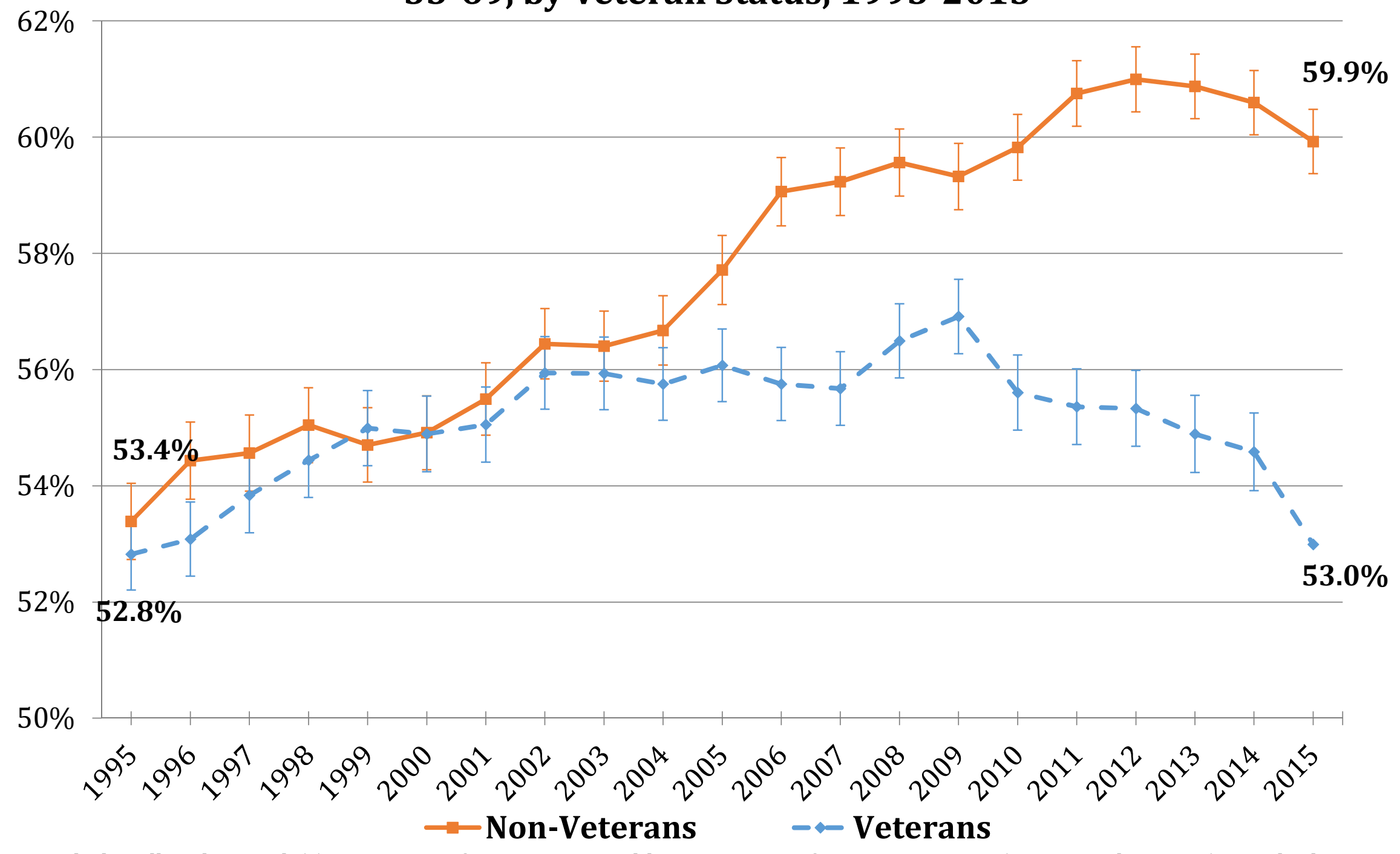

Includes all males aged 55-69 at time of survey in monthly CPS surveys from January 1995 to December 2015. Graphed are estimated labor force participation rates after conditioning for year and age fixed effects. The baseline estimate for the 55-69 age group is $53 \%$. 
Table 1: Distribution of Veterans by Year of Birth

\begin{tabular}{|c|c|c|c|c|}
\hline YOB & All Males & \% Veterans & \% (Vietnam Era | Vet) & \% (BOG | Vietnam Era) \\
\hline $\mathbf{1 9 3 9}$ & 6348 & $43.2 \%$ & $32.9 \%$ & $53.4 \%$ \\
\hline $\mathbf{1 9 4 0}$ & 6879 & $39.7 \%$ & $39.7 \%$ & $49.1 \%$ \\
\hline $\mathbf{1 9 4 1}$ & 6984 & $39.7 \%$ & $50.0 \%$ & $50.1 \%$ \\
\hline $\mathbf{1 9 4 2}$ & 7804 & $39.7 \%$ & $60.9 \%$ & $50.5 \%$ \\
\hline $\mathbf{1 9 4 3}$ & 8686 & $41.2 \%$ & $74.4 \%$ & $42.7 \%$ \\
\hline $\mathbf{1 9 4 4}$ & 8317 & $40.4 \%$ & $83.2 \%$ & $45.8 \%$ \\
\hline $\mathbf{1 9 4 5}$ & 8428 & $42.4 \%$ & $92.0 \%$ & $47.6 \%$ \\
\hline $\mathbf{1 9 4 6}$ & 9066 & $45.7 \%$ & $94.7 \%$ & $51.5 \%$ \\
\hline $\mathbf{1 9 4 7}$ & 12032 & $47.1 \%$ & $97.3 \%$ & $51.0 \%$ \\
\hline $\mathbf{1 9 4 8}$ & 11201 & $43.1 \%$ & $97.1 \%$ & $49.7 \%$ \\
\hline $\mathbf{1 9 4 9}$ & 11185 & $37.5 \%$ & $95.3 \%$ & $46.4 \%$ \\
\hline $\mathbf{1 9 5 0}$ & 11684 & $30.3 \%$ & $93.2 \%$ & $41.3 \%$ \\
\hline $\mathbf{1 9 5 1}$ & 11906 & $25.3 \%$ & $91.0 \%$ & $34.6 \%$ \\
\hline $\mathbf{1 9 5 2}$ & 12355 & $20.7 \%$ & $88.1 \%$ & $28.4 \%$ \\
\hline $\mathbf{1 9 5 3}$ & 12548 & $18.2 \%$ & $78.8 \%$ & $28.2 \%$ \\
\hline $\mathbf{1 9 5 4}$ & 13047 & $16.1 \%$ & $72.2 \%$ & $25.4 \%$ \\
\hline $\mathbf{1 9 5 5}$ & 13394 & $14.8 \%$ & $64.4 \%$ & $24.0 \%$ \\
\hline $\mathbf{1 9 5 6}$ & 13513 & $14.6 \%$ & $48.9 \%$ & $24.4 \%$ \\
\hline $\mathbf{1 9 5 7}$ & 13910 & $14.7 \%$ & $25.3 \%$ & $60.0 \%$ \\
\hline $\mathbf{1 9 5 8}$ & 13602 & $13.1 \%$ & $0.4 \%$ & $46.9 \%$ \\
\hline $\mathbf{1 9 4 4 - 1 9 5 3}$ & 108722 & $34.2 \%$ & $92.3 \%$ & \\
\hline
\end{tabular}

Sample includes males in Veterans Supplement of CPS $(1995,1997,1999,2001,2003,2005,2007,2009$, and 2010-2015). Yeear of Birth defined as age at time of survey minus survey year. Veterans defined as having previously served in the Armed Forces. Columns $3 \& 4$ are limited to 2005 and later. Vietnam era defined as veterans who reported a service period of 1964-1975. BOG defined as Vietnam era veterans who reported active duty in Vietnam/Cambodia/Laos (or surounding waters) any time from 1961 to 1975. 
Table 2: Characteristics of Sample in Pre-Policy Period (1995-2001)

\begin{tabular}{cccc}
\hline Variable & BOG & NOG & Difference \\
\hline Northeast & Census Region & & \\
Midwest & $18.8 \%$ & $20.5 \%$ & $-1.7^{* *}$ \\
South & $25.8 \%$ & $24.9 \%$ & 0.9 \\
West & $29.7 \%$ & $31.1 \%$ & -1.4 \\
& $25.7 \%$ & $23.5 \%$ & $2.2^{* *}$ \\
Age & Demographics & & \\
White & 50.20 & 49.73 & $0.47^{* * *}$ \\
Black & $88.4 \%$ & $89.5 \%$ & $-1.1^{*}$ \\
Hispanic & $8.7 \%$ & $7.6 \%$ & $1.2^{* *}$ \\
Married & $3.6 \%$ & $2.5 \%$ & $1.1^{* * *}$ \\
HSgrad or less & $73.9 \%$ & $75.5 \%$ & $-1.5^{*}$ \\
College degree & $40.4 \%$ & $36.6 \%$ & $3.7^{* * *}$ \\
Work-preventing Disability & $34.8 \%$ & $39.7 \%$ & $-5.0^{* * *}$ \\
In Labor Force & $7.3 \%$ & $5.0 \%$ & $2.3^{* * *}$ \\
Weekly Earnings (2015 \$) & $86.8 \%$ & $90.2 \%$ & $-3.3^{* * *}$ \\
& 917.35 & 992.28 & $-74.93^{* * *}$ \\
VADC Receipt & Service-Related & & \\
CDR 50+ & $14.8 \%$ & $6.3 \%$ & $8.5^{* * *}$ \\
Served 5+ years & $4.1 \%$ & $1.0 \%$ & $3.1^{* * *}$ \\
Military Service since 1990 & $16.8 \%$ & $15.9 \%$ & 0.9 \\
\hline
\end{tabular}

Sample includes 5,391 BOG and 6,198 NOG veterans from the Veterans Supplement to the CPS $(1995,1997,1999,2001)$. BOG is defined as Vietnam era veterans who reported active duty in Vietnam/Cambodia/ Laos (or surounding waters) any time from 1961 to 1975. Weekly earnings data is only available for 4 th and 8 th month in sample, and equal zero for those not employed.

$$
\text { *** } \mathrm{p}<0.01,{ }^{* *} \mathrm{p}<0.05,{ }^{*} \mathrm{p}<0.1
$$


Table 3: DC Receipt for BOG vs. NOG Veterans, 1995-2015

\begin{tabular}{|c|c|c|c|c|c|c|}
\hline & \multicolumn{3}{|c|}{ DC Receipt } & \multicolumn{3}{|c|}{$\mathrm{CDR} \geq 50 \%$} \\
\hline & $(1)$ & $(2)$ & $(3)$ & $(4)$ & $(5)$ & $(6)$ \\
\hline BOG & $\begin{array}{c}8.51^{* * *} \\
(0.72)\end{array}$ & $\begin{array}{l}7.98^{* * *} \\
(0.94)\end{array}$ & $\begin{array}{c}7.90^{* * *} \\
(1.12)\end{array}$ & $\begin{array}{c}2.75^{* * *} \\
(0.40)\end{array}$ & $\begin{array}{c}2.75^{* * *} \\
(0.53)\end{array}$ & $\begin{array}{c}2.98^{* * *} \\
(0.60)\end{array}$ \\
\hline BOG*(1995-97) & & $\begin{array}{c}1.38 \\
(1.46)\end{array}$ & & & $\begin{array}{l}-0.00 \\
(0.80)\end{array}$ & \\
\hline BOG*(Year Pre-Trend) & & & $\begin{array}{l}-0.27 \\
(0.34)\end{array}$ & & & $\begin{array}{c}0.10 \\
(0.18)\end{array}$ \\
\hline $\mathrm{BOG}^{*}(2003-2009)$ & $\begin{array}{l}2.23^{* *} \\
(1.04)\end{array}$ & $\begin{array}{l}2.76^{* *} \\
(1.21)\end{array}$ & $\begin{array}{l}2.84^{* *} \\
(1.35)\end{array}$ & $\begin{array}{c}3.94^{* * *} \\
(0.64)\end{array}$ & $\begin{array}{c}3.93^{* * *} \\
(0.73)\end{array}$ & $\begin{array}{c}3.71^{* * *} \\
(0.78)\end{array}$ \\
\hline $\mathrm{BOG}^{*}(2010-2015)$ & $\begin{array}{c}9.80^{* * *} \\
(1.18)\end{array}$ & $\begin{array}{c}10.33^{* * *} \\
(1.32)\end{array}$ & $\begin{array}{c}10.41^{* * *} \\
(1.45)\end{array}$ & $\begin{array}{c}8.72^{* * *} \\
(0.78)\end{array}$ & $\begin{array}{c}8.72^{* * *} \\
(0.86)\end{array}$ & $\begin{array}{c}8.49^{* * *} \\
(0.90)\end{array}$ \\
\hline Mean of Dependent Variable & 15.27 & 15.27 & 15.27 & 6.07 & 6.07 & 6.07 \\
\hline Observations & 125,711 & 125,711 & 125,711 & 125,711 & 125,711 & 125,711 \\
\hline R-Squared & 0.06 & 0.06 & 0.06 & 0.05 & 0.05 & 0.05 \\
\hline
\end{tabular}

\section{Notes:}

1. All specifications include year, month, and age fixed effects and indicators for White, Black, and HS graduate or less; regressions are weighted with vetcps weights. Models are estimated as linear probability models.

2. DC Receipt and CDR $\geq 50 \%$ are indicator variables equal to 100 for receiving DC benefits or having a combined disability rating of $50 \%$ or above.

3. BOG is an indicator variable for having Boots on the Ground. BOG*(1995-97) is an interaction between BOG and an indicator for sample years 1995 and 1997; BOG interactions with 2003-2009 and 2010-2015 are defined similarly.

There is no interaction between BOG and the sample years 1999 and 2001.

4. BOG*(Year Pre-Trend) is an interaction between BOG and a linear year trend (year-2001 until 2001 and 0 thereafter)

5. Standard errors are clustered at the person level. Statistical significance at the $10 \%, 5 \%$, and $1 \%$ level are indicated by *, **, and ${ }^{* * *}$, respectively. 
Table 4: Labor Force Participation for BOG vs. NOG Veterans, 1995-2015

\begin{tabular}{|c|c|c|c|c|c|c|c|c|}
\hline & \multicolumn{2}{|c|}{ In Labor Force } & \multicolumn{2}{|c|}{ Not in Labor Force: Disabled } & \multicolumn{2}{|c|}{ Not in Labor Force: Retired } & \multicolumn{2}{|c|}{ Not in Labor Force: Other } \\
\hline & $(1)$ & $(2)$ & (3) & $(4)$ & $(5)$ & $(6)$ & $(7)$ & $(8)$ \\
\hline BOG & $\begin{array}{c}-2.75^{* * *} \\
(0.75)\end{array}$ & $\begin{array}{c}-2.85^{* * *} \\
(1.02)\end{array}$ & $\begin{array}{l}2.18^{* * *} \\
(0.57)\end{array}$ & $\begin{array}{c}2.26^{* * *} \\
(0.78)\end{array}$ & $\begin{array}{c}0.41 \\
(0.42)\end{array}$ & $\begin{array}{c}0.35 \\
(0.61)\end{array}$ & $\begin{array}{c}0.16 \\
(0.25)\end{array}$ & $\begin{array}{c}0.24 \\
(0.31)\end{array}$ \\
\hline BOG*(1995-97) & & $\begin{array}{c}0.24 \\
(1.45)\end{array}$ & & $\begin{array}{c}-0.21 \\
(1.11)\end{array}$ & & $\begin{array}{c}0.17 \\
(0.79)\end{array}$ & & $\begin{array}{l}-0.19 \\
(0.52)\end{array}$ \\
\hline $\mathrm{BOG}^{*}(2003-2009)$ & $\begin{array}{l}-1.17 \\
(1.20)\end{array}$ & $\begin{array}{l}-1.08 \\
(1.38)\end{array}$ & $\begin{array}{c}0.88 \\
(0.84)\end{array}$ & $\begin{array}{c}0.80 \\
(0.99)\end{array}$ & $\begin{array}{c}0.47 \\
(0.89)\end{array}$ & $\begin{array}{c}0.53 \\
(0.99)\end{array}$ & $\begin{array}{c}-0.18 \\
(0.33)\end{array}$ & $\begin{array}{l}-0.26 \\
(0.38)\end{array}$ \\
\hline $\mathrm{BOG}^{*}(2010-2015)$ & $\begin{array}{l}-2.54^{*} \\
(1.30)\end{array}$ & $\begin{array}{l}-2.45^{*} \\
(1.48)\end{array}$ & $\begin{array}{c}0.45 \\
(0.84)\end{array}$ & $\begin{array}{c}0.37 \\
(0.99)\end{array}$ & $\begin{array}{c}2.18^{*} \\
(1.12)\end{array}$ & $\begin{array}{c}2.24^{*} \\
(1.20)\end{array}$ & $\begin{array}{c}-0.08 \\
(0.32)\end{array}$ & $\begin{array}{l}-0.15 \\
(0.36)\end{array}$ \\
\hline Mean of Dependent Variable & 63.80 & 63.80 & 8.41 & 8.41 & 25.81 & 25.81 & 1.98 & 1.98 \\
\hline Observations & 125,711 & 125,711 & 125,711 & 125,711 & 125,711 & 125,711 & 125,711 & 125,711 \\
\hline R-Squared & 0.21 & 0.21 & 0.03 & 0.03 & 0.26 & 0.26 & 0.00 & 0.00 \\
\hline
\end{tabular}

Notes:

1. All specifications include year, month, and age fixed effects and indicators for White, Black, and HS graduate or less; regressions are weighted with vetcps weights. Models are estimated as linear probability models.

2. All dependent variables are indicator variables equal to 100. The means of In Labor Force and the three NILF variables sum to one.

3. BOG is an indicator variable for having Boots on the Ground. BOG*(1995-97) is an interaction between BOG and an indicator for sample years 1995 and 1997;

BOG interactions with 2003-2009 and 2010-2015 are defined similarly. There is no interaction between BOG and 1999 and 2001.

4. Standard errors are clustered at the person level. Statistical significance at the $10 \%, 5 \%$, and $1 \%$ level are indicated by *, ${ }^{* *}$, and ${ }^{* * *}$, respectiv ely. 
Table 5: Type of Employment for BOG vs. NOG Veterans, 1995-2015

\begin{tabular}{|c|c|c|c|c|c|c|c|c|}
\hline & \multicolumn{2}{|c|}{ Employed } & \multicolumn{2}{|c|}{ Working for Others } & \multicolumn{2}{|c|}{ Self-Employed } & \multicolumn{2}{|c|}{ Unemployed } \\
\hline & (1) & $(2)$ & (3) & $(4)$ & $(5)$ & $(6)$ & $(7)$ & $(8)$ \\
\hline BOG & $\begin{array}{c}-3.43^{* * *} \\
(0.80)\end{array}$ & $\begin{array}{c}-2.93^{* * *} \\
(1.08)\end{array}$ & $\begin{array}{c}0.07 \\
(1.02)\end{array}$ & $\begin{array}{c}1.35 \\
(1.34)\end{array}$ & $\begin{array}{c}-3.50^{* * *} \\
(0.75)\end{array}$ & $\begin{array}{c}-4.28^{* * *} \\
(0.97)\end{array}$ & $\begin{array}{l}0.68^{* *} \\
(0.29)\end{array}$ & $\begin{array}{c}0.09 \\
(0.37)\end{array}$ \\
\hline BOG*(1995-97) & & $\begin{array}{l}-1.31 \\
(1.57)\end{array}$ & & $\begin{array}{l}-3.33 \\
(2.06)\end{array}$ & & $\begin{array}{c}2.02 \\
(1.55)\end{array}$ & & $\begin{array}{c}1.55^{* * *} \\
(0.60)\end{array}$ \\
\hline BOG*(2003-2009) & $\begin{array}{c}-1.41 \\
(1.25)\end{array}$ & $\begin{array}{l}-1.91 \\
(1.45)\end{array}$ & $\begin{array}{l}-2.76^{*} \\
(1.46)\end{array}$ & $\begin{array}{c}-4.04^{* *} \\
(1.70)\end{array}$ & $\begin{array}{c}1.36 \\
(1.01)\end{array}$ & $\begin{array}{c}2.13^{*} \\
(1.18)\end{array}$ & $\begin{array}{c}0.23 \\
(0.43)\end{array}$ & $\begin{array}{c}0.83^{*} \\
(0.49)\end{array}$ \\
\hline $\mathrm{BOG}^{*}(2010-2015)$ & $\begin{array}{c}-1.87 \\
(1.34)\end{array}$ & $\begin{array}{l}-2.37 \\
(1.52)\end{array}$ & $\begin{array}{c}-5.23^{* * *} \\
(1.45)\end{array}$ & $\begin{array}{c}-6.50^{* * *} \\
(1.69)\end{array}$ & $\begin{array}{c}3.36^{* * *} \\
(0.96)\end{array}$ & $\begin{array}{c}4.13^{* * *} \\
(1.14)\end{array}$ & $\begin{array}{l}-0.68 \\
(0.43)\end{array}$ & $\begin{array}{l}-0.08 \\
(0.48)\end{array}$ \\
\hline Mean of Dependent Variable & 60.91 & 60.91 & 50.61 & 50.61 & 10.30 & 10.30 & 2.89 & 2.89 \\
\hline Observations & 125,711 & 125,711 & 125,711 & 125,711 & 125,711 & 125,711 & 125,711 & 125,711 \\
\hline R-Squared & 0.20 & 0.20 & 0.16 & 0.16 & 0.01 & 0.01 & 0.01 & 0.01 \\
\hline $\begin{array}{l}\text { Notes: } \\
\text { 1. All specifications include year, } \\
\text { Models are estimated as linear pr } \\
\text { 2. All dependent variables are ind } \\
\text { 3. BOG is an indicator variable fo } \\
\text { BOG interactions with } 2003-200 \\
\text { 4. Standard errors are clustered a }\end{array}$ & $\begin{array}{l}\text { or variabl } \\
\text { ving Boot } \\
\text { d 2010-20 } \\
\text { e person le }\end{array}$ & $\begin{array}{l}\text { d effects } \\
\text { lal to } 100 \\
\text { e Grounc } \\
\text { e defined } \\
\text { tatistical }\end{array}$ & $\begin{array}{l}\text { ans of Wo } \\
\text { (1995-97) } \\
\text { y. There is } \\
\text { ance at the }\end{array}$ & $\begin{array}{l}\text { e, Black, an } \\
\text { for Others } \\
\text { interaction } \\
\text { teraction b }\end{array}$ & $\begin{array}{l}\text { raduate o } \\
\text { elf-Emplo } \\
\text { een BOG a } \\
\text { en BOG an } \\
\text { lane indi }\end{array}$ & $\begin{array}{l}\text { egressio } \\
\text { to the } \\
\text { hdicator } \\
\text { and } 200 \\
* * *\end{array}$ & $\begin{array}{l}\text { eighted wit } \\
\text { ployed. } \\
\text { le years } 19\end{array}$ & d 1997; \\
\hline
\end{tabular}


Table 6: Types of Self Employment for BOG vs. NOG Veterans, 1995-2015

\begin{tabular}{|c|c|c|c|c|c|c|c|c|c|c|}
\hline & \multicolumn{2}{|c|}{ Incorporated } & \multicolumn{2}{|c|}{ Unincorporated } & \multicolumn{2}{|c|}{ Construction } & \multicolumn{2}{|c|}{ Professional/Business Services } & \multicolumn{2}{|c|}{ Other Industries } \\
\hline & $(1)$ & $(2)$ & (3) & (4) & (5) & $(6)$ & $(7)$ & $(8)$ & (9) & $(10)$ \\
\hline BOG & $\begin{array}{c}-1.47^{* * *} \\
(0.46)\end{array}$ & $\begin{array}{l}-1.48^{* *} \\
(0.58)\end{array}$ & $\begin{array}{c}-2.03^{* * *} \\
(0.62)\end{array}$ & $\begin{array}{c}-2.79^{* * *} \\
(0.81)\end{array}$ & $\begin{array}{l}-0.36 \\
(0.36)\end{array}$ & $\begin{array}{l}-0.67 \\
(0.47)\end{array}$ & $\begin{array}{l}-0.97^{* *} \\
(0.39)\end{array}$ & $\begin{array}{c}-1.07^{* *} \\
(0.51)\end{array}$ & $\begin{array}{c}-2.17^{* * *} \\
(0.57)\end{array}$ & $\begin{array}{c}-2.54^{* * *} \\
(0.73)\end{array}$ \\
\hline BOG* $^{*}(1995-97)$ & & $\begin{array}{c}0.04 \\
(0.97)\end{array}$ & & $\begin{array}{c}1.98 \\
(1.27)\end{array}$ & & $\begin{array}{c}0.79 \\
(0.74)\end{array}$ & & $\begin{array}{c}0.28 \\
(0.79)\end{array}$ & & $\begin{array}{c}0.96 \\
(1.20)\end{array}$ \\
\hline BOG*(2003-2009) & $\begin{array}{c}0.63 \\
(0.64)\end{array}$ & $\begin{array}{c}0.64 \\
(0.73)\end{array}$ & $\begin{array}{c}0.73 \\
(0.83)\end{array}$ & $\begin{array}{c}1.49 \\
(0.97)\end{array}$ & $\begin{array}{c}0.12 \\
(0.49)\end{array}$ & $\begin{array}{c}0.43 \\
(0.57)\end{array}$ & $\begin{array}{c}0.34 \\
(0.51)\end{array}$ & $\begin{array}{c}0.44 \\
(0.61)\end{array}$ & $\begin{array}{c}0.90 \\
(0.78)\end{array}$ & $\begin{array}{c}1.26 \\
(0.91)\end{array}$ \\
\hline $\mathrm{BOG}^{*}(2010-2015)$ & $\begin{array}{l}1.43^{* *} \\
(0.58)\end{array}$ & $\begin{array}{l}1.44^{* *} \\
(0.68)\end{array}$ & $\begin{array}{l}1.93^{* *} \\
(0.79)\end{array}$ & $\begin{array}{c}2.69^{* * *} \\
(0.94)\end{array}$ & $\begin{array}{l}-0.21 \\
(0.44)\end{array}$ & $\begin{array}{c}0.09 \\
(0.53)\end{array}$ & $\begin{array}{l}1.20^{* *} \\
(0.50)\end{array}$ & $\begin{array}{l}1.30 * * \\
(0.60)\end{array}$ & $\begin{array}{c}2.38^{* * *} \\
(0.73)\end{array}$ & $\begin{array}{c}2.74^{* * *} \\
(0.86)\end{array}$ \\
\hline Mean of Dependent Variablt & 3.79 & 3.79 & 6.51 & 6.51 & 1.97 & 1.97 & 2.36 & 2.36 & 5.96 & 5.96 \\
\hline Observations & 125,711 & 125,711 & 125,711 & 125,711 & 125,711 & 125,711 & 125,711 & 125,711 & 125,711 & 125,711 \\
\hline R-Squared & 0.01 & 0.01 & 0.01 & 0.01 & 0.00 & 0.00 & 0.01 & 0.01 & 0.01 & 0.01 \\
\hline
\end{tabular}

Notes:

1. All specifications include year, month, and age fixed effects and indicators for White, Black, and HS graduate or less; regressions are weighted with vetcps weights.

Models are estimated as linear probability models.

2. All dependent variables are indicator variables equal to 100, and the sum of Incorporated and Unincorporated equals the sum of Construction,

Professional/Business Services, and Other Industries.

3. BOG is an indicator variable for having Boots on the Ground. BOG*(1995-97) is an interaction between BOG and an indicator for sample years 1995 and 1997;

BOG interactions with 2003-2009 and 2010-2015 are defined similarly. There is no interaction between BOG and 1999 and 2001.

4. Standard errors are clustered at the person level. Statistical significance at the $10 \%, 5 \%$, and $1 \%$ level are indicated by $*, * *$, and ${ }^{* * *}$, respectively. 
Table 7: Hours and Earnings for BOG vs. NOG Veterans, 1995-2015

\begin{tabular}{|c|c|c|c|c|c|c|c|c|}
\hline & \multicolumn{2}{|c|}{ Usual Hours } & \multicolumn{2}{|c|}{ Any Weekly Earnings } & \multicolumn{2}{|c|}{ Weekly Earnings } & \multicolumn{2}{|c|}{ Log Weekly Earnings } \\
\hline & $(1)$ & $(2)$ & (3) & $(4)$ & (5) & (6) & $(7)$ & $(8)$ \\
\hline BOG & $\begin{array}{c}-1.36^{* * *} \\
(0.40)\end{array}$ & $\begin{array}{l}-0.70 \\
(0.53)\end{array}$ & $\begin{array}{l}-2.41^{* *} \\
(0.98)\end{array}$ & $\begin{array}{c}-1.72 \\
(1.28)\end{array}$ & $\begin{array}{c}-62.06^{* * *} \\
(19.25)\end{array}$ & $\begin{array}{l}-45.51 * \\
(25.70)\end{array}$ & $\begin{array}{c}-0.19^{* * *} \\
(0.07)\end{array}$ & $\begin{array}{c}-0.15 \\
(0.09)\end{array}$ \\
\hline BOG*(1995-97) & & $\begin{array}{l}-1.72^{* *} \\
(0.80)\end{array}$ & & $\begin{array}{c}-1.82 \\
(1.97)\end{array}$ & & $\begin{array}{l}-43.73 \\
(38.21)\end{array}$ & & $\begin{array}{c}-0.13 \\
(0.14)\end{array}$ \\
\hline BOG*(2003-2009) & $\begin{array}{l}-0.47 \\
(0.59)\end{array}$ & $\begin{array}{c}-1.12 \\
(0.68)\end{array}$ & $\begin{array}{l}-2.03 \\
(1.49)\end{array}$ & $\begin{array}{c}-2.72 \\
(1.71)\end{array}$ & $\begin{array}{l}-36.34 \\
(26.91)\end{array}$ & $\begin{array}{l}-52.91 * \\
(31.86)\end{array}$ & $\begin{array}{l}-0.14 \\
(0.10)\end{array}$ & $\begin{array}{c}-0.18 \\
(0.12)\end{array}$ \\
\hline $\mathrm{BOG}^{*}(2010-2015)$ & $\begin{array}{c}-0.48 \\
(0.59)\end{array}$ & $\begin{array}{l}-1.14^{*} \\
(0.68)\end{array}$ & $\begin{array}{l}-3.55^{* *} \\
(1.41)\end{array}$ & $\begin{array}{c}-4.24^{* * *} \\
(1.63)\end{array}$ & $\begin{array}{c}-6.31 \\
(24.28)\end{array}$ & $\begin{array}{l}-22.86 \\
(29.65)\end{array}$ & $\begin{array}{c}-0.21^{* *} \\
(0.10)\end{array}$ & $\begin{array}{c}-0.26^{* *} \\
(0.11)\end{array}$ \\
\hline Mean of Dependent Variable & 24.40 & 24.40 & 56.34 & 56.34 & 655.81 & 655.81 & 3.86 & 3.86 \\
\hline Observations & 125,711 & 125,711 & 28,037 & 28,037 & 28,037 & 28,037 & 28,037 & 28,037 \\
\hline R-Squared & 0.21 & 0.21 & 0.22 & 0.22 & 0.18 & 0.18 & 0.24 & 0.24 \\
\hline
\end{tabular}

Notes:

1. All specifications include year, month, and age fixed effects and indicators for White, Black, and HS graduate or less; regressions are weighted with vetcps weights. Models are estimated as linear probability models.

2. Any Weekly Earnings is an indicator variable and the other dependent variables are continuous. Earnings data is only collected during the outgoing rotation month and self-employment income is not observed (self-employed are dropped). Earnings are adjusted to 2015 dollars, and equal to zero for non-employed.

Log Earnings takes the natural log of (1+Weekly Earnings).

3. BOG is an indicator variable for having Boots on the Ground. BOG*(1995-97) is an interaction between BOG and an indicator for sample years 1995 and 1997; BOG interactions with 2003-2009 and 2010-2015 are defined similarly. There is no interaction between BOG and 1999 and 2001.

4. Standard errors are clustered at the person level. Statistical significance at the $10 \%, 5 \%$, and $1 \%$ level are indicated by ***, and ***, respectively. 
Table 8: Spousal Employment Outcomes for BOG vs. NOG Veterans, 1995-2015

\begin{tabular}{|c|c|c|c|c|c|c|c|c|}
\hline & \multicolumn{2}{|c|}{ Family Income $<\$ 50 \mathrm{~K}$} & \multicolumn{2}{|c|}{ Spousal Weekly Earnings } & \multicolumn{2}{|c|}{ Log Spousal Earnings } & \multicolumn{2}{|c|}{ Log(Own + Spouse Earnings $)$} \\
\hline & $(1)$ & $(2)$ & (3) & (4) & (5) & $(6)$ & $(7)$ & $(8)$ \\
\hline BOG & $\begin{array}{c}-0.55^{* * *} \\
(0.14)\end{array}$ & $\begin{array}{c}-0.60^{* * *} \\
(0.18)\end{array}$ & $\begin{array}{c}0.27 \\
(17.42)\end{array}$ & $\begin{array}{c}13.24 \\
(22.93)\end{array}$ & $\begin{array}{c}0.00 \\
(0.09)\end{array}$ & $\begin{array}{c}0.13 \\
(0.12)\end{array}$ & $\begin{array}{l}-0.01 \\
(0.06)\end{array}$ & $\begin{array}{c}0.11 \\
(0.08)\end{array}$ \\
\hline BOG*(1995-97) & & $\begin{array}{c}0.12 \\
(0.27)\end{array}$ & & $\begin{array}{c}-34.18 \\
(35.40)\end{array}$ & & $\begin{array}{l}-0.35^{*} \\
(0.19)\end{array}$ & & $\begin{array}{c}-0.32^{* * *} \\
(0.12)\end{array}$ \\
\hline $\mathrm{BOG}^{*}(2003-2009)$ & $\begin{array}{c}0.23 \\
(0.19)\end{array}$ & $\begin{array}{c}0.27 \\
(0.22)\end{array}$ & $\begin{array}{c}-50.97^{* *} \\
(24.19)\end{array}$ & $\begin{array}{c}-63.93^{* *} \\
(28.44)\end{array}$ & $\begin{array}{l}-0.14 \\
(0.13)\end{array}$ & $\begin{array}{l}-0.27^{*} \\
(0.15)\end{array}$ & $\begin{array}{c}-0.26^{* * *} \\
(0.10)\end{array}$ & $\begin{array}{c}-0.38^{* * *} \\
(0.11)\end{array}$ \\
\hline $\mathrm{BOG}^{*}(2010-2015)$ & $\begin{array}{l}2.65^{* *} \\
(1.27)\end{array}$ & $\begin{array}{l}2.70^{* *} \\
(1.27)\end{array}$ & $\begin{array}{l}-10.84 \\
(22.47)\end{array}$ & $\begin{array}{c}-23.80 \\
(26.96)\end{array}$ & $\begin{array}{l}-0.03 \\
(0.12)\end{array}$ & $\begin{array}{l}-0.17 \\
(0.14)\end{array}$ & $\begin{array}{c}-0.30^{* * *} \\
(0.11)\end{array}$ & $\begin{array}{c}-0.42^{* * *} \\
(0.12)\end{array}$ \\
\hline Mean of Dependent Variable & 15.56 & 15.56 & 440.84 & 440.84 & 3.55 & 3.55 & 5.29 & 5.29 \\
\hline Observations & 92,830 & 92,830 & 19,348 & 19,348 & 19,348 & 19,348 & 19,348 & 19,348 \\
\hline R-Squared & 0.27 & 0.27 & 0.06 & 0.06 & 0.11 & 0.11 & 0.23 & 0.23 \\
\hline
\end{tabular}

Notes:

1. All specifications include year, month, and age fixed effects and indicators for White, Black, and HS graduate or less; regressions are weighted with vetcps weights Models are estimated as linear probability models.

2. Family Income $<\$ 50 \mathrm{~K}$ is an indicator variable, and the other dependent variables are continuous. Earnings data is only collected during the outgoing rotation month, and self-employment income is not observed (self-employed are dropped). Earnings are adjusted to 2015 dollars, and equal to zero for non-employed. Log Spousal Earnings takes the nautral log of $(1+$ Spousal Weekly Earnings); $\log (0 w n+S p o u s e)$ does the same for $(1+$ Spouse $+0 w n)$.

3. BOG is an indicator variable for having Boots on the Ground. BOG*(1995-97) is an interaction between BOG and an indicator for sample years 1995 and 1997; BOG interactions with 2003-2009 and 2010-2015 are defined similarly. There is no interaction between BOG and 1999 and 2001.

4. Standard errors are clustered at the person level. Statistical significance at the $10 \%, 5 \%$, and $1 \%$ level are indicated by ${ }^{*}, * *$, and ${ }^{* * *}$, respectively. 


\section{Appendix Tables}


Figure A1: Age Distribution of Veterans CPS Sample

\begin{tabular}{|c|c|c|c|c|c|c|c|c|c|c|c|c|c|c|c|}
\hline & 1995 & 1997 & 1999 & 2001 & 2003 & 2005 & 2007 & 2009 & 2010 & 2011 & 2012 & 2013 & 2014 & 2015 & Total \\
\hline 42 & 167 & & & & & & & & & & & & & & 167 \\
\hline 43 & 217 & & & & & & & & & & & & & & 217 \\
\hline 44 & 226 & 188 & & & & & & & & & & & & & 414 \\
\hline 45 & 292 & 167 & & & & & & & & & & & & & 459 \\
\hline 46 & 352 & 194 & 138 & & & & & & & & & & & & 684 \\
\hline 47 & 456 & 237 & 184 & & & & & & & & & & & & 877 \\
\hline 48 & 485 & 274 & 201 & 186 & & & & & & & & & & & 1146 \\
\hline 49 & 382 & 354 & 239 & 210 & & & & & & & & & & & 1185 \\
\hline 50 & 298 & 446 & 305 & 259 & 203 & & & & & & & & & & 1511 \\
\hline 51 & 308 & 279 & 380 & 308 & 193 & & & & & & & & & & 1468 \\
\hline 52 & & 242 & 418 & 351 & 229 & 176 & & & & & & & & & 1416 \\
\hline 53 & & 222 & 323 & 366 & 280 & 188 & & & & & & & & & 1379 \\
\hline 54 & & & 290 & 458 & 323 & 247 & 159 & & & & & & & & 1477 \\
\hline 55 & & & 255 & 339 & 364 & 309 & 173 & & & & & & & & 1440 \\
\hline 56 & & & & 290 & 440 & 296 & 210 & 154 & & & & & & & 1390 \\
\hline 57 & & & & 303 & 332 & 373 & 280 & 184 & 126 & & & & & & 1598 \\
\hline 58 & & & & & 274 & 395 & 331 & 234 & 157 & 126 & & & & & 1517 \\
\hline 59 & & & & & 269 & 297 & 343 & 248 & 191 & 146 & 139 & & & & 1633 \\
\hline 60 & & & & & & 263 & 434 & 287 & 222 & 190 & 149 & 132 & & & 1677 \\
\hline 61 & & & & & & 272 & 296 & 312 & 260 & 214 & 199 & 137 & 112 & & 1802 \\
\hline 62 & & & & & & & 244 & 418 & 271 & 242 & 177 & 163 & 154 & 106 & 1775 \\
\hline 63 & & & & & & & 264 & 286 & 357 & 293 & 241 & 174 & 144 & 144 & 1903 \\
\hline 64 & & & & & & & & 236 & 234 & 316 & 261 & 225 & 196 & 152 & 1620 \\
\hline 65 & & & & & & & & 241 & 236 & 247 & 312 & 274 & 262 & 179 & 1751 \\
\hline 66 & & & & & & & & & 205 & 205 & 244 & 306 & 296 & 232 & 1488 \\
\hline 67 & & & & & & & & & & 197 & 204 & 229 & 321 & 245 & 1196 \\
\hline 68 & & & & & & & & & & & 169 & 218 & 236 & 287 & 910 \\
\hline 69 & & & & & & & & & & & & 155 & 208 & 225 & 588 \\
\hline 70 & & & & & & & & & & & & & 164 & 174 & 338 \\
\hline 71 & & & & & & & & & & & & & & 152 & 152 \\
\hline Total & 3183 & 2603 & 2733 & 3070 & 2907 & 2816 & 2734 & 2600 & 2259 & 2176 & 2095 & 2013 & 2093 & 1896 & 35178 \\
\hline
\end{tabular}

All male veterans in VETCPS with YOB 1944-1953, where YOB is defined as age at time of survey minus survey year. The drop in sample size in years 2010 - 2015 is due to nonresponse in the veterans supplement. We make up for this in our estimation by upweighting the remaining observations by age group and military service period. 


\section{Figure A2: Industries for Self-Employed and Other Workers, 2003 - 2015}

\begin{tabular}{|c|c|c|c|c|c|c|}
\hline \multirow{2}{*}{ Industry } & \multicolumn{2}{|c|}{ Non-Veteran } & \multicolumn{2}{|c|}{ NOG } & \multicolumn{2}{|c|}{ BOG } \\
\hline & Self-Employed & Other & Self-Employed & Other & Self-Employed & Other \\
\hline Agriculture, Forestry, Fishing, Hunting & $12.6 \%$ & $1.7 \%$ & $11.1 \%$ & $1.4 \%$ & $13.7 \%$ & $1.1 \%$ \\
\hline Mining & $0.4 \%$ & $1.3 \%$ & $0.6 \%$ & $1.2 \%$ & $0.3 \%$ & $1.3 \%$ \\
\hline Construction & $18.1 \%$ & $8.4 \%$ & $17.8 \%$ & $7.6 \%$ & $16.8 \%$ & $8.1 \%$ \\
\hline Manufacturing & $4.4 \%$ & $17.1 \%$ & $5.6 \%$ & $17.1 \%$ & $4.8 \%$ & $17.8 \%$ \\
\hline Wholesale and Retail Trade & $11.3 \%$ & $13.9 \%$ & $11.0 \%$ & $12.9 \%$ & $13.1 \%$ & $13.8 \%$ \\
\hline Transportation and Utilities & $4.4 \%$ & $8.8 \%$ & $3.4 \%$ & $11.3 \%$ & $5.6 \%$ & $13.7 \%$ \\
\hline Information & $1.3 \%$ & $2.3 \%$ & $1.2 \%$ & $2.0 \%$ & $0.7 \%$ & $2.0 \%$ \\
\hline Financial Activities & $8.7 \%$ & $5.8 \%$ & $10.1 \%$ & $5.5 \%$ & $11.0 \%$ & $4.7 \%$ \\
\hline Professional and Business Services & $20.9 \%$ & $9.7 \%$ & $21.5 \%$ & $9.9 \%$ & $19.4 \%$ & $9.0 \%$ \\
\hline Educational and Health Services & $6.4 \%$ & $15.3 \%$ & $7.1 \%$ & $13.2 \%$ & $4.4 \%$ & $11.9 \%$ \\
\hline Leisure and Hospitality & $5.8 \%$ & $5.0 \%$ & $3.6 \%$ & $3.6 \%$ & $3.6 \%$ & $3.9 \%$ \\
\hline Other Services & $5.8 \%$ & $4.4 \%$ & $6.9 \%$ & $4.1 \%$ & $6.6 \%$ & $3.4 \%$ \\
\hline Public Administration & $0.0 \%$ & $6.4 \%$ & $0.0 \%$ & $10.1 \%$ & $0.0 \%$ & $9.3 \%$ \\
\hline Armed Forces & $0.0 \%$ & $0.0 \%$ & $0.0 \%$ & $0.0 \%$ & $0.0 \%$ & $0.1 \%$ \\
\hline
\end{tabular}

Sample includes INLF males with YOB 1944-1953 in the 2003 to 2015 VETCPS. YOB is defined as age at time of survey minus survey year, and Self-employed is defined as either "self-employed incorporated" or "self-employed unincorporated" worker classification. 
Figure A3: $\log (1+$ Annual Earnings) for Self-Employed versus Others in Labor Force, 2010 - 2015
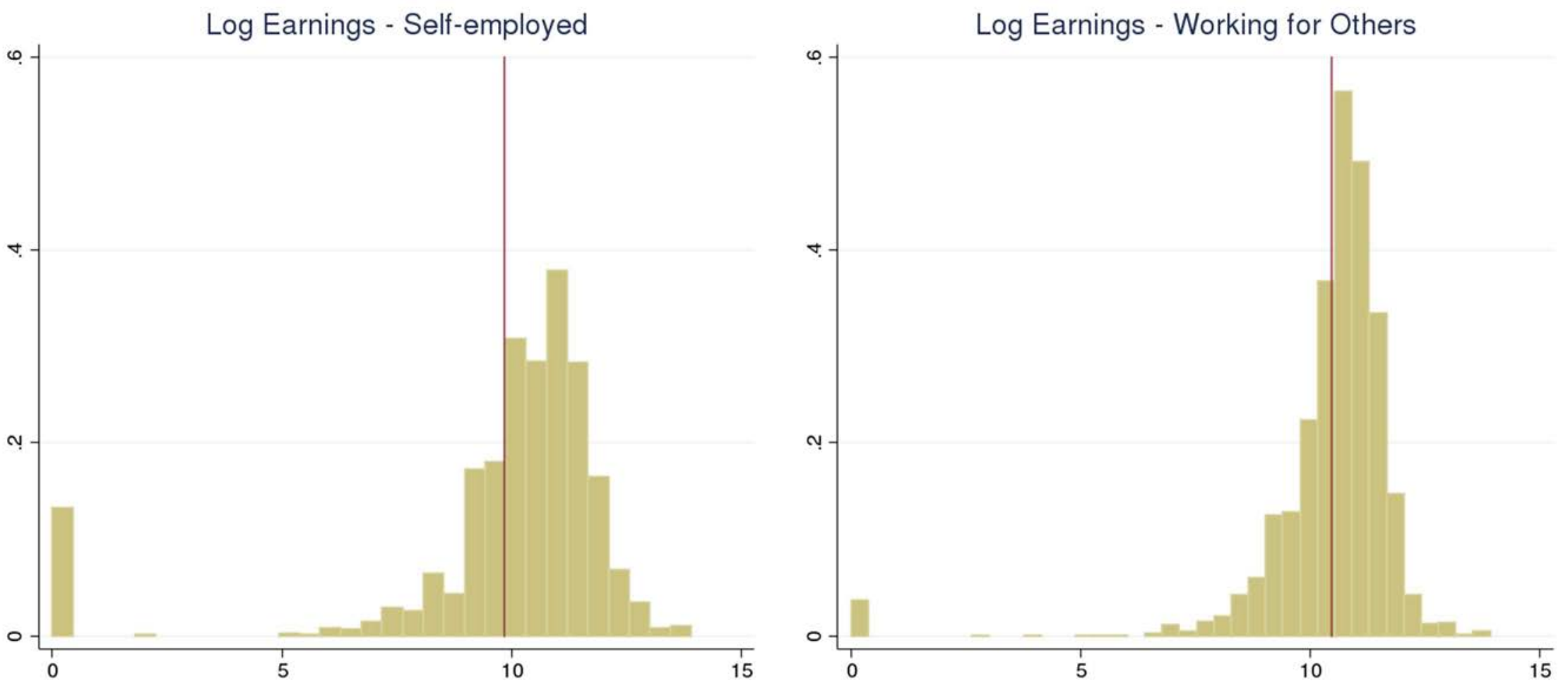

Sample includes employed males with YOB 1944-1953 and reporting Vietnam Era service in the 2010 to 2015 March CPS. YOB is defined as age at time of survey minus survey year, and Vietnam Era is defined as veterans who reported a service period of 1964-1975. Mean log earnings are graphed as a vertical line. 